\section{Intersections}

Canadian Journal of Music

Revue canadienne de musique
Intersections CANADIAN JOURAL OF MUSIC

\title{
Des orgues et des hommes à Québec sous le Régime français : sur la piste du premier facteur d'orgue du Canada
}

\section{Paul-André Dubois}

Volume 38, numéro 1-2, 2018

URI : https://id.erudit.org/iderudit/1071677ar

DOI : https://doi.org/10.7202/1071677ar

Aller au sommaire du numéro

Éditeur(s)

Canadian University Music Society / Société de musique des universités canadiennes

ISSN

1911-0146 (imprimé)

1918-512X (numérique)

Découvrir la revue

Citer cet article

Dubois, P.-A. (2018). Des orgues et des hommes à Québec sous le Régime français : sur la piste du premier facteur d'orgue du Canada. Intersections, 38(1-2), 121-151. https://doi.org/10.7202/1071677ar
Résumé de l'article

Écrit sous forme d'enquête policière, cet article se penche sur une affirmation émise par le premier biographe de Mgr de Laval (1623-1708) voulant qu'un ecclésiastique, dont il tait le nom, ait fabriqué des orgues de bois pour les églises de la ville de Québec et de ses environs. L'auteur de cet article formule ici une hypothèse de recherche sur l'identité et la vie de ce premier facteur d'orgue canadien en s'appuyant sur un faisceau d'indices trouvés dans les archives relatives à l'époque de la Nouvelle-France. In fine, cet article se veut une réflexion sur le contexte culturel qui prévaut à Québec au tournant du XVIII ${ }^{\mathrm{e}}$ siècle et une invitation faite aux chercheurs à poursuivre cette investigation qui relance le débat sur la genèse de la facture d'orgue au Canada.
Copyright @ C Canadian University Music Society / Société de musique des universités canadiennes, 2020
Ce document est protégé par la loi sur le droit d'auteur. L’utilisation des services d’Érudit (y compris la reproduction) est assujettie à sa politique d'utilisation que vous pouvez consulter en ligne.

https://apropos.erudit.org/fr/usagers/politique-dutilisation/ 


\title{
DES ORGUES ET DES HOMMES À QUÉBEC SOUS LE RÉGIME FRANÇAIS : SUR LA PISTE DU PREMIER FACTEUR D'ORGUE DU CANADA
}

\author{
Paul-André Dubois
}

L'histoire de l'orgue en Nouvelle-France a presqu'essentiellement été le fait de la musicologue Élisabeth Gallat-Morin qui, depuis la découverte du Livre d'orgue de Montréal en 1978, n'a cessé de fouiller les archives de la colonie canadienne afin d'y débusquer toutes les mentions relatives à cet instrument et à sa littérature musicale. Depuis la parution de la Vie musicale en Nouvelle-France (Gallat-Morin et Pinson 2003) et, plus récemment d'un ouvrage rétrospectif sur l'orgue dans la colonie française (Gallat-Morin 2012, 143-173), on croyait avoir tout dit sur le sujet. De nouvelles données historiques permettent pourtant aujourd'hui de pousser plus avant notre connaissance du monde organistique de la colonie en levant le voile sur des aspects demeurés obscurs dans les ouvrages de musicologie, et tout particulièrement sur un certain ecclésiastique qui aurait fabriqué des orgues à Québec vers la fin du XVII ${ }^{2}$ è siècle.

Dans ses Mémoires sur la vie de M. de Laval, premier évêque de Québec, le chanoine Bertrand de Latour (1761) signale la présence à Québec d'un ecclésiastique ayant fabriqué des orgues de bois sur le modèle de celles que le vicaire apostolique avait rapportées de France en 1663 . Ce facteur d'orgue amateur en a intrigué plus d'un, et pour cause. Si l'affirmation de Latour est juste, il s'agirait du premier facteur d'orgue ayant exercé son activité au Canada. Jusqu'ici, personne n'a réussi à percer le mystère entourant l'activité de cet ecclésiastique artisan dont le nom est demeuré inconnu. Aujourd'hui, un faisceau d'indices nous conduisent vers la personne tant recherchée. Cela dit, l'état d'avancement de la recherche sur le sujet, largement entravée par de trop nombreuses pertes documentaires, ne permet toutefois que d'avancer une hypothèse sur l'identité de cet individu, hypothèse étayée par un appareil critique certes, mais demandant néanmoins à être confirmée par l'éventuelle découverte d'autres pièces d'archives qui permettront d'établir hors de tout doute que le sous-diacre François Grouard (1662-1743) est bien l'homme auquel Latour fait référence sans le nommer. C'est en questionnant les origines et l'itinéraire de cet ecclésiastique de Québec que se révèle en palimpseste l'identité de notre organier amateur. À travers les réalisations et les déboires de Grouard, la vie qui bat s'exprime et, dans la foulée, se manifeste l'importance des clercs non-prêtres dans l'activité 
artistique des institutions religieuses, mais aussi la précarité de leur statut au sein du clergé séculier.

La quête d'informations sur l'identité du tout premier facteur d'orgue du Canada nous plonge au cœur d'un réseau d'ecclésiastiques et d'artisans gravitant autour du Séminaire de Québec. Agissant tantôt comme commanditaires, tantôt comme artisans, si ce n'est comme organistes, tous les acteurs impliqués dans le projet de fabrication d'un instrument pour la nouvelle chapelle du séminaire de Québec érigée entre 1692 et 1696, sont reliés entre eux par des liens quasi organiques. À travers les entrelacs complexes que tissent ces relations parentales et professionnelles, des individus et même des instruments refont surface. Le présent article propose donc une incursion dans le microcosme québécois de l'orgue sous le Régime français au cours de l'intervalle 1685-1725, avec comme objectif affiché de leur exposer combien la formation d'organistes et l'émergence in situ d'un facteur d'orgue à une époque si précoce sont intimement reliées dans le contexte colonial et ne se peuvent se concevoir qu'à la faveur d'une conjoncture particulière, voire d'une constellation humaine qui ne s'est rencontrée qu'exceptionnellement dans l'histoire de l'Église et des arts en Nouvelle-France. À travers la vie diaphane de François Grouard (1662-1743) s'ébauche une histoire peu connue de l'orgue dans la capitale du Canada au moment où l'Église diocésaine de Québec prend forme.

\section{UNE ÉGLISE DIOCÉSAINE EN CONSTRUCTION}

Le 12 novembre 1684, les cloches de Notre-Dame de Québec sonnent à toute volée. Mgr de Laval entre processionnellement dans la cathédrale, suivi de Lefebvre de La Barre, gouverneur-général de la colonie, de l'intendant Jacques de Meulles, des membres du Conseil souverain, de la noblesse et autres magistrats, derrière lesquels figurent les différents corps du clergé. Titulaire du siège de Québec depuis dix ans, le prélat procède enfin à l'érection canonique de l'évêché, de la cathédrale et de son chapitre (Langevin 1874, 195). En cette journée d'allégresse, le chant, l'orgue et les instruments de musique résonnent tandis que l'artillerie gronde pour solenniser l'évènement. Parmi les chanoines figurent entre autres Jean-François Buisson, Jean Guyon et Louis Soumande, assistés par les chapelains du nouveau chapitre, à savoir Philippe Boucher et François Grouard, tous deux sous-diacres.

Après avoir triomphé de périls considérables, l'Église de Québec connaît une croissance dans les années 1670 . Certes, l'enthousiasme de cette période de consolidation dialogue en contrepoint avec une vie faite d'inquiétude et de misère. Au milieu de la grisaille d'un quotidien particulièrement rude, Mgr de Laval sait faire espérer son peuple. Tout reste à créer, sinon à relever. Dans la décennie 1680, le soutien du monarque en faveur de sa colonie et la multiplication des ménages résultant des politiques de peuplement permettent enfin à l'Église du Canada d'entrevoir des lendemains prometteurs. Portée par l'enthousiasme que le prélat sait insuffler à son entourage, la nouvelle église diocésaine prend forme, grâce à l'appui d'un clergé séculier et régulier qui épouse fidèlement les vues de Laval quant à l'avenir de cette Église naissante. Aux côtés des autres 
institutions religieuses, le grand séminaire de Québec (1663) et le petit séminaire dit de l'Enfant-Jésus (1668) jouent un rôle important dans la cléricalisation du paysage urbain de Québec. Loin de se cantonner aux lettres, l'enseignement dispensé aux garçons de ces deux institutions inclut l'apprentissage des arts mécaniques comme délassement ${ }^{1}$, quand ce n'est pas par nécessité.

Comme le souligne l'historien de l'art Jean Trudel, les contrats d'engagements des sculpteurs Michel Fauchois et Samuel Genner par le Séminaire de Québec en 1675 attestent chez l'évêque la volonté de s'entourer d'une main d'œuvre masculine capable de répondre aux besoins d'une Église diocésaine en plein essor (Trudel 1969). Dans un document que l'on attribue à l'intendant de Meulles, on peut lire que les séminaristes sans talents signalés pour l'étude, apprennent divers métiers, tels que «la menuiserie, la sculpture, la peinture, la dorure, pour l'ornement des églises, la maçonne et la charpente. Il y a de plus tailleurs, cordonniers, taillandiers, serruriers, couvreurs qui apprennent ces métiers aux enfants du pays» (Gosselin 1911, 354-355). Lors de sa visite épiscopale de 1685, Mgr de Saint-Vallier, le successeur de Laval, examine chacun des 31 garçons de l'école du Cap-Tourmente confiée aux soins de deux ecclésiastiques du Séminaire. Dix-neuf garçons sont alors appliqués aux études tandis que onze de leurs confrères se livrent à l'apprentissage de l'agriculture et autres connaissances utiles pour leur établissement à la campagne.

Loin de n'être qu'une pépinière de vocations sacerdotales, le séminaire de Québec se veut également un milieu où le goût de l'artiste et le savoir-faire de l'artisan se conjuguent au service de la foi et de la civilisation chrétienne française. Dans un contexte où tout reste à édifier, tous les talents sont mis à profit. Chez Mgr de Laval et son entourage, cette sensibilité pour les arts se traduit dans l'intérêt que le prélat porte à certains élèves particulièrement talentueux. Parmi ceux-là, figure le jeune Jean Guyon. Recruté sur la Côte de Beaupré où ses parents sont établis, il est admis au séminaire. Doué pour le dessin, Mgr de Laval l'autorise à se rendre à Paris pour y prendre des leçons de peinture ${ }^{2}$. Jacques Leblond de Latour, fils d'un peintre fort estimé à Bordeaux, est également recruté par l'évêque pour le Canada en 1690. À son arrivée, Leblond de Latour s'adonne activement à la sculpture, tout en franchissant les étapes qui le mèneront vers la prêtrise. Comme le font remarquer les historiens de l'art, l'arrivée de Leblond de Latour exerce une influence décisive sur le milieu artistique évoluant dans l'orbite du Séminaire de Québec (Porter et Bélisle 1986; Payer et Drouin 2016; Trudel 1969). Puis viennent d'autres artisans, non moins importants pour aider les élèves de l'institution dans leur apprentissage

1 Par opposition aux arts libéraux, les arts mécaniques comprennent, entre autres choses, les techniques de travail du métal et du bois. Dans son Dictionnaire universel, Antoine Furetière établit la distinction entre les arts libéraux et les arts mécaniques. Au sujet des premiers, il écrit: «Les Arts Liberaux, sont ceux qui sont nobles, \& honnêtes; comme la Rhetorique, la Musique, la Peinture, la Sculpture, l'Architecture, la Grammaire, la Geometrie, \&c. On les appelle Arts Liberaux, parce qu'ils [... ] consistent plus dans les opérations de l'esprit que dans ceux de la main». Quant aux seconds, il dit: «Les Arts Mechaniques, sont ceux où l'on travaille plus de la main, \& du corps, que de l'esprit: ce sont d'ordinaire ceux qui nous fournissent les necesfitez de la vie, comme celui des Horlogers, Tourneurs, Charpentiers, Fondeurs, Boulengers, Cordonniers, etc.» (Furetière 1727, article «Art»).

2 Annales du Séminaire de Québec, ms. 2a, p. 8-11, Archives du séminaire de Québec (ASQ). 
de la sculpture et de la dorure, à savoir les Denis Mallet, Charles Vézina et Pierre-Gabriel Le Prévost. On relève en effet les noms de Leblond et de Denis Mallet dans les livres de compte pour l'année $1696^{3}$. Parmi les réalisations attribuées à ces équipes formées autant de professionnels, d'ecclésiastiques que d'élèves doués pour les travaux manuels figurent bien évidemment la chapelle du séminaire de Québec édifiée et décorée entre 1690 et 1696 . Bacqueville de La Potherie qui la visite lors de son séjour à Québec en 1698 en salue la beauté architecturale rehaussée par de grands tableaux, un maître-autel remarquable et par la sculpture en général, alors évaluée à 10000 écus 4 . À l'évidence, les ecclésiastiques doués pour les arts mécaniques ne font pas défaut, sans parler des petites mains qui, loin de vivre cette expérience comme une servitude, croyons-nous, ont au contraire l'impression de travailler au grand-œuvre du Séminaire. En cette époque d'édification matérielle, le milieu du Séminaire de Québec fédère alors tous les talents disponibles pour réaliser et concrétiser les projets de prédilection du prélat. Mais il manque à la chapelle du séminaire un élément de mobilier pour compléter son décor et en exalter la beauté : un orgue.

\section{UN ORgue POUR LA NOUVELLE CHAPELLE DU SÉMINAIRE}

En homme de la Réforme catholique, Mgr de Laval accorde une grande importance au chant ecclésiastique dans les cérémonies liturgiques. Dans son séminaire, grands et petits doivent connaître le plain-chant ou, en d'autres termes, le chant grégorien. Alors qu'il n'est que clerc, l'abbé Henri-Jean Tremblay est recruté en 1687 pour le séminaire de Québec par le prélat, parce qu'il «sait fort bien son plain-chant et a bonne voix; c'est lui qui soustenoit icy [au séminaire

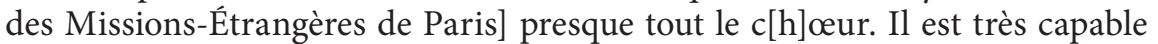
de le montrer» (Langevin 1874, 136)5. Dans une même perspective de solennisation liturgique, l'orgue doit être également présent dans la chapelle des séminaristes autant pour rehausser l'éclat des cérémonies que soutenir le chant. L'église paroissiale de Québec dispose d'un instrument depuis 1657, lequel est remplacé par celui que Mgr de Laval rapporte avec lui de France en 1663, nous l'avons dit. La nouvelle chapelle du séminaire a besoin de son propre instrument. Cet orgue sera construit au début de la décennie 1690.

Les livres de compte du séminaire de Québec font état de deux paiements à ce sujet en septembre 1693: «Payé à Liénard pour travail fait à l'orgue neuf, 208

3 Livre de comptes, C4, p. 473-474, ASQ.

4 Bacqueville nous a laissé une description de l'intérieur de la nouvelle chapelle du séminaire: «La Chapelle avec la Sacristie a quarante pieds de long. La Sculpture que l'on estime dix mille écus en est très-belle; elle a été faite par des Séminaristes qui n’ont rien épargné pour mettre l'ouvrage dans sa perfection. Le maitre Autel est un ouvrage d'architecture à la Corinthienne; les murailles sont revêtues de Lambris et de sculpture, dans les quelles sont plusieurs grands tableaux, les ornemens qui les accompagnent se vont terminer sous la corniche de la voûte qui est à pans, sur lesquels sont des compartimens en lozange, accompagnez d'ornemens de sculpture peints et dorez» (Bacqueville 1753, 234-235).

5 «Lettre de Mgr de Laval à Messieurs de Bernières, des Maizerets et Glandelet, Paris, 9 juin $1687 »$. 
livres $^{6}{ }$. Il s'agit ici du menuisier Jean-François Liénard dit Durbois (1657-1731), un artisan connu et apprécié des institutions religieuses qui recourent à ses services, notamment les Ursulines de Québec qui lui font réparer leur tabernacle?. Cet important salaire payé à Liénard suggère qu'il travaille au gros-œuvre de l'orgue, soit au buffet, voire à l'édification du jubé où allait être installé le nouvel instrument. Au passage, notons que depuis 1699, le sculpteur Denis Mallet est le beau-frère de Jean-François Liénard dit Durbois par son mariage avec la sœur de ce dernier, Geneviève Liénard dit Durbois. Gardons en mémoire ces noms car si Québec est un tout petit univers, celui de l'orgue l'est encore davantage. En somme, le projet global de la nouvelle chapelle du séminaire rassemble des artisans unis entre eux par des liens familiaux et professionnels qui touchent autant des ecclésiastiques que des séculiers.

Ces mêmes livres de comptes rapportent encore qu'en septembre 1693 l'on a «payé à Grouard pour l'orgue, 57 livres 9 sols ${ }^{8}$ ». En 1965, un article publié dans la Revue de l'Université Laval suggérait que cet ouvrier était Jacques Grouard, ancien élève du petit séminaire et désormais serrurier et bourgeois à Québec. Autant qu'on puisse en juger à partir des livres de comptes de la paroisse de Notre-Dame de Québec, Jacques Grouard (le frère cadet du diacre François Grouard) effectue régulièrement de petits travaux de réfections des serrures, des pentures et autres 9 .

Au décès du père de Jacques Grouard en 1667, sa mère Marie Languille, ayant déjà quatre enfants à sa charge, se remarie avec François Hurault, bourgeois de la haute-ville et serrurier. Né en 1663, Jacques est recruté pour le petit séminaire par Mgr de Laval alors qu'il a 10 ans. Au recensement de 1681, alors âgé de 18 ans, il est toujours pensionnaire au séminaire, tout comme François, son aîné d'un an qui se prépare à embrasser l'état ecclésiastique. Selon les recherches effectuées par Peter N. Moogk, Jacques Grouard ferait partie de ces garçons ayant été initiés au travail manuel spécialisé dans les ateliers que comportait le bâtiment du séminaire ${ }^{10}$. Dès cette époque, les directeurs de l'institution divisent les écoliers en deux classes, l'une composée des élèves propres aux études, donc éventuellement aptes à cheminer vers le sacerdoce, et l'autre constituée de garçons appelés à devenir artisans, fautes d'aptitudes pour les études ou l'inclination vers l'état ecclésiastique. Jacques Grouard se range parmi ceux-ci. Parmi les métiers alors offerts, l'apprentissage de la serrurerie est signalé dans un mémoire produit vers cette époque ${ }^{11}$. Jacques Grouard de-

6 Livre de comptes, C4, p. 353, ASQ. Cette information a été publiée pour la première fois dans la Revue de l'Université Laval, vol. 20, no. 1, 1965, p. 22.

7 Jean-Pierre Asselin, «Registre des recettes et dépenses de l'église Sainte-Anne du Petit-Cap (1659-1700), RAPQ, tome 45, 1967, p. 243.

8 Livre de comptes, C4, p. 353, ASQ.

9 Livres de comptes des marguilliers de Notre-Dame-de-Québec, , CM2/C1, 1, vol. 1, fol. 127v, 353, Archives de l'archidiocèse de Québec (AAQ).

10 Peter N. Moogk, «Réexamen de l'École des arts et métiers de Saint-Joachim », RHAF 291, 1975, p. 3-29.

11 [Anonyme], «Instruction pour establir les manufactures", Polygraphie 6, no. 22, ASQ; Doreen Walker, «Instruction pour establir les manufactures, A key document in the art history of New France», Annales d'histoire de l'art canadien, vol. II, no. 1, 1975, p. 1-18. 
vient en effet serrurier tout comme son beau-père François Hurault et, à ce titre, reste en relations soutenues avec le séminaire comme maître-ouvrier ${ }^{12}$. Il est à noter que Jacques Grouard appartient désormais à un réseau d'artisans qui se distingue par des habiletés manuelles avérées, notamment dans la micro-mécanique. Or, l'orgue est l'un des instruments qui nécessitent le plus d'habiletés dans ce domaine. À cet égard, les livres de compte de la paroisse Notre-Dame de Québec, pour les années 1664-1670, révèlent en effet que l'installation de l'instrument apporté par Mgr de Laval a requis en 1664 les services de menuisiers, mais aussi de serruriers et d'arquebusiers, parmi lesquels on rencontre Mathurin Orieux ou Horieux, armurier-serrurier et Jean de Lespinasse, maitre arquebusier ${ }^{13}$. De même, l'entretien et les réparations exigés par l'instrument de Notre-Dame ont nécessité les services de Jean Soulard et de Nicolas Gauvreau, tous deux serruriers-arquebusiers ${ }^{14}$, lesquels sont qualifiés de témoins et amis lors du mariage de la demi-sœur de Jacques Grouard en $1685^{15}$. Voilà donc un milieu où le génie pour la mécanique se mêle à une certaine connaissance technique de l'orgue.

Chose certaine, si le menuisier Jean-François Liénard et le serrurier Jacques Grouard ont participé d'une manière ou d'une autre à la fabrication de l'orgue de la chapelle du séminaire (tuyaux de bois, sommiers, claviers, buffet) ou à son installation, aucun des deux n'est ecclésiastique. Or, Latour est formel: en 1664, « on commença à se servir des orgues que M. l'Évêque avoit apportées de Paris [en 1663]. Sur ce modelle, un Ecclésiastique, qui a du génie pour la méchanique, en a fait dans plusieurs Églises avec du bois seulement, qui rendent un son fort agréable» (Latour 1761, 172). Habituellement très disert sur les acteurs de la petite histoire, le premier biographe de Mgr de Laval tait le nom de cet ecclésiastique, soit à la demande de ce dernier, soit pour d'autres raisons. À l'évidence, le gros travail de Liénard dit Durbois a été coordonné par quelqu'un ayant acquis, au moins par observation, une compréhension de la facture d'orgue, et dans le cas qui nous intéresse plus particulièrement, par un ecclésiastique ayant une sensibilité pour la mécanique et pouvant disposer de ressources professionnelles et de moyens pour réaliser un tel travail. Les minces indices recueillis dans les livres de compte relus à la lumière du contexte d'effervescence artistique qui prévaut en ces années où l'on construit et orne la nouvelle chapelle du séminaire, conduisent logiquement vers un seul individu susceptible d'avoir été le maître d'œuvre de l'orgue du séminaire: François Grouard, ecclésiastique.

12 En 1689, Jacques Grouard épouse Marie Têtu en 1689 à Notre-Dame de Québec. Le couple s'établit sur la rue de La Montagne où Jacques Grouard organise son atelier de maître-serrurier. Le propre fils, également prénommé Jacques, fréquentera lui aussi le séminaire. Les annales de l’institution rapportent que «Jacques Grouard, âgé d'environ 15 ans est entré le 17 de mai [1706], il est sorti sur la fin de l'année 1709, ayant commencé la Rhétorique, n'ayant pas la volonté de rester au séminaire", ASQ, Annales, année 1706, ms. 2a, p. 35; ASQ, Livre de comptes, C4, p. 197, 198, 213, 214, 316, 317, 459.

13 Livres de comptes de N.-D.-de-Québec, CM2/C1, 1, vol. 1, fol. 11v, AAQ.

14 Livres de comptes de N.-D.-de-Québec, CM2/C1, 1, vol. 1, p. 6, 7, 14., 15v, AAQ.

15 Registres des insinuations de la Prévôté de Québec, vol. 1 (anciennement registres 1, 2 et 3), $1^{\mathrm{er}}$ mars 1667-25 septembre 1696, p. 515-520. 


\section{François GrouARD, ECCLÉSIASTIQUE ET PREMIER FACTEUR D'Orgue de la NOUVELle-France?}

Né à Québec le 31 juillet 1662, François Grouard est le premier fils de Richard Grouard dit Larose et de Marie Languille, alors établis dans la haute ville de Québec et le frère de Jacques Grouard (1663-1712), dont il a été question. François Grouard fait son entrée au petit séminaire de Québec le 24 septembre 1673 à l'âge de 11 ans $^{16}$. Plusieurs documents cités par A. Gosselin dans son ouvrage sur l'Instruction au Canada sous le Régime français montrent que les élèves du séminaire étaient initiés très tôt au travail manuel. L'article 15 de l'ancien règlement du séminaire stipule que tous les pensionnaires «auront tous quelques mestiers pour s'occuper hors le temps de leurs exercices et tascheront que leurs travaux soient utiles au Séminaire et aux Églises» (Gosselin 1911, 350-51). En période de colonisation, le prêtre de paroisse doit savoir travailler de ses mains. Dans cette perspective, la formation ecclésiastique et l'apprentissage des arts mécaniques ne se contredisent aucunement. Le séminaire de Québec ne fait d'ailleurs pas figure d'exception à ce sujet. Parmi les loisirs recommandables pour les ecclésiastiques, le prêtre et pédagogue Charles Demia recommande, par exemple, «le travail manuel du jardin, du tour, de la peinture, et autre art bienséant, la musique, les instruments, bannissant les airs mondains et lascifs » (Démia 1683, 55). Qu'un jeune ecclésiastique se soit essayé à toucher l'orgue et même ait envisagé d'en construire un de petite dimension ne présente donc rien d'étonnant dans un contexte colonial où tout ce qui peut contribuer à la décoration des églises et à l'éclat des cérémonies est fortement encouragé.

Si d'aucuns prétendent que les jeunes Canadiens manquent d'application pour l'étude (Charlevoix 1744, 255), Bertrand de Latour, qui fut chanoine au chapitre de la cathédrale de Québec de 1729 à 1731, salue néanmoins leur génie pour la mécanique (Latour 1761,99 ). Il n'est d'ailleurs pas le seul à faire cette observation. Ayant été professeur de grammaire au collège de Québec de 1705 à 1709, le jésuite François-Xavier de Charlevoix qui connait très bien le monde estudiantin de Québec abonde dans le même sens lorsqu'il écrit à propos de ces mêmes jeunes Canadiens que "personne ne peut leur contester un génie rare pour les Mécaniques : ils n'ont presque pas besoin de maitres pour y exceller, et on en voit tous les jours qui réussissent dans les métiers sans en avoir fait d'apprentissage» (Charlevoix 1744, 255). Issu d'un milieu de serruriers et d'arquebusiers, dont certains ont acquis une connaissance de la mécanique de l'orgue - notamment l'arquebusier Jean Soulard, dont il a été question -, François Grouard correspond assez bien au profil de l'autodidacte canadien dont parle Charlevoix. Cela dit, un facteur d'orgue, même amateur, ne surgit pas ex nihilo. Un contexte très particulier en favorise l'apparition, pensons ici au réseau socioprofessionnel de la famille Hurault-Grouard dont les ressources sont mises au service de l'édification de l'église diocésaine et ce, tant au sens spirituel que matériel. Avec le recul du temps, tout porte à croire que cette facture d'orgue locale, revêtait une dimension collective, ne serait-ce que pour les matériaux, les savoir-faire et même les outils, notamment au regard des pièces

16 Annales du Séminaire de Québec, ms. 2a, p. 4, ASQ. 
métalliques, d'où le recours aux services du propre frère de François Grouard en 1693, à savoir Jacques Grouard, serrurier.

\section{UN ORGUE DE « BOIS SEULEMENT »}

Si on ne connaît rien du devis de l'instrument apporté par Mgr de Laval en 1663, nous savons cependant que les quelques instruments construits par le sous-diacre François Grouard ne comportaient que des tuyaux de bois, sans doute des tuyaux carrés, peut-être fabriqués à partir de planches de pin. Selon Latour qui les entendit alors qu'il était chanoine au chapitre de Québec, ces petits instruments rendaient «un son fort agréable» (Latour 1761, 172). Ce commentaire suggère aujourd'hui au chercheur que les instruments de Grouard offraient une certaine rondeur sonore. Selon Robin Côté, de la Maison JugetSinclair, facteurs d'orgues et créateurs d'instruments dits historiques, les orgues de bois, auxquels Bertrand de Latour fait allusion, ne comportaient fort probablement que deux jeux, soit un Bourdon de 8 pieds $^{17}$, (jeu à la base des mélanges caractéristiques de l'orgue français de cette époque) et une Flûte de 4 pieds, jeu naturellement complémentaire au Bourdon, selon le traité de Mersenne ${ }^{18}$. Expérimenté en la matière, Robin Côté explique que la fabrication manuelle de tuyaux en bois supposait un travail énorme de la part de l'artisan, surtout pour les petits tuyaux. Par conséquent, il serait étonnant que Grouard ait fabriqué un jeu aigu de 2 pieds en bois dans ces conditions. Surtout que le jeu de l'orgue, dont certains séminaristes de cette époque apprenaient les rudiments, avait principalement pour fonction de soutenir la psalmodie et non de répondre aux exigences du répertoire organistique de cette époque (quoique, malgré les limites que comportaient de tels instruments, certains élèves durent bien s'essayer à quelques pages des maîtres de l'orgue). Quant aux jeux graves, un bourdon de 16 pieds aurait été disproportionné pour des instruments d'aussi petites tailles. À ce propos, Robin Côté souligne que de tels cabinets d'orgues, fabriqués à Québec dans la décennie 1690, devaient se présenter comme de grandes armoires moulurées et décorées, dépourvues de tuyaux de façade. Audessus du clavier, un grillage ou simplement des portes permettaient au son de s'échapper du buffet (fig. 1). Selon le même, qui a pu observer de pareils instruments au cours de sa carrière, le buffet de l'orgue (l'endroit qui renferme les tuyaux) avait probablement une largeur 5 pieds $(1,5 \mathrm{~m})$ sur une profondeur de trois pieds $(91 \mathrm{~cm})$, tandis que sa hauteur atteignait 9 pieds $(2,7 \mathrm{~m})$. Le clavier se situait à 3 pieds $(91 \mathrm{~cm})$ du sol, permettant ainsi à l'organiste de s'asseoir devant l'instrument. En ce qui regarde l'alimentation en air, deux soufflets cunéiformes devaient être placés à l'arrière ou dans le soubassement de l'instrument, tout dépendant de l'ingéniosité du constructeur.

17 Il s'agit ici de la mesure du tuyau le plus long de la série de tuyaux que comporte ce jeu.

18 Correspondance personnelle de l'auteur avec Robin Côté. Mersenne écrit: «Le Bourdon est de 8 pieds bouché et est de bois ou d'étoffe. Il fait l'unisson avec la Montre, mais il est plus doux parce qu'il est bouché. L'autre Bourdon est de 4 pieds bouché ou de 8 pieds ouvert en façon de flûte. Il est à l'octave des précédents et peut être d'étain ou de bois». Marin Mersenne, Traicté de l'Orgve, Paris, Ballard, 1635, Proposition XXXI. 


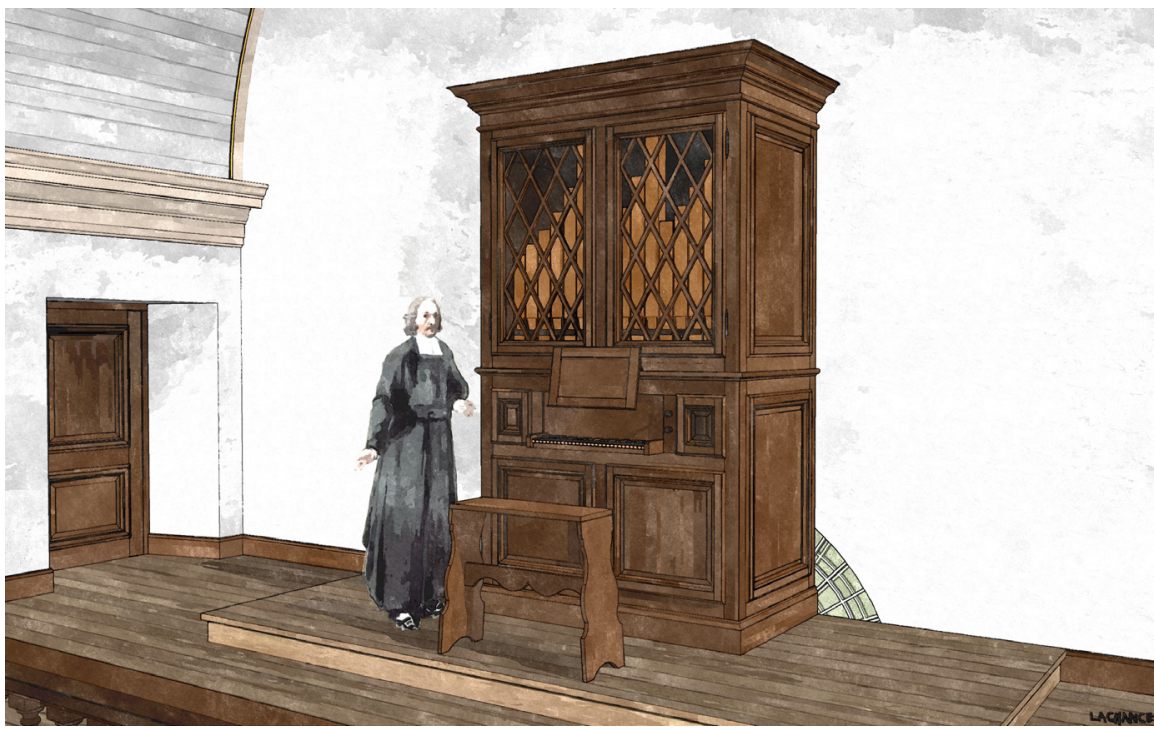

Figure 1. Orgue de bois placé à la tribune de la chapelle du palais épiscopal, ca 1700

Il n'est pas inutile de présenter ici quelques-unes des très nombreuses pièces qui composent un tel instrument. Sans décrire dans le menu détail la mécanique complexe de l'orgue, rappelons seulement qu'au cœur de celui-ci, on trouve le sommier qui agit comme la pièce maitresse de l'instrument parce qu'il répartit l'air sous pression dans les tuyaux des jeux qui ont été sélectionnés par l'organiste. La fabrication de cette pièce exige une très grande précision pour en garantir l'étanchéité, sans quoi les fuites d'air feront corner les tuyaux d'autres jeux ${ }^{19}$. Produit par une soufflerie actionnée manuellement par un assistant pendant que l'organiste s'exécute, l'air est acheminé dans la laye, sorte de caisson inférieur du sommier dont l'étanchéité se doit également d'être parfaite. À chaque note du clavier touchée par l'organiste correspond une soupape qui conduit l'air vers la gravure, traversant le sommier d'avant en arrière. De gauche à droite, une pièce de bois mobile, appelée "registre», laisse entrer l'air dans les tuyaux du jeu choisi par l'organiste. C'est ainsi que le vent est acheminé au bon tuyau. L'ensemble de tous ces mécanismes est renfermé dans le buffet. La précision, l'étanchéité et la souplesse du mouvement sont autant de qualités essentielles au fonctionnement correct de l'orgue, d'où les réparations fréquentes que l'on relève dans les livres de comptes de la paroisse de Notre-Dame de Québec. Même construit uniquement de bois, un orgue nécessite la présence de certaines pièces métalliques, telles que des tiges, des ressorts et autres actions mécaniques sous-jacentes au fonctionnement du clavier. Ainsi en 1677 , la paroisse paie 18 sols pour «un paquet de petites lignes pour les orgues ${ }^{20}$ ", probablement des vergettes de bois ou des fils métalliques.

19 Terme vieilli signifiant faire sonner de la corne, de la trompe. Son indésirable dans le contexte de l'orgue.

20 Livres de comptes de N.-D.-de-Québec, $\mathrm{CM}_{2} / \mathrm{C}_{1}$, 1, vol. 1, p. 42v, AAQ. 
Pour réaliser un tel instrument nécessitant une excellente compréhension du mécanisme de l'orgue, il est essentiel de disposer d'outils spécialisés et d'une expertise dans le domaine de la micro-mécanique, telle que pouvaient la détenir des arquebusiers et des serruriers. À l'observation in situ et à un bon entendement pour la mécanique s'est peut-être ajoutée la consultation d'un ouvrage spécialisé capable de guider l'apprenti facteur d'orgue de Québec, notamment au regard de questions techniques et acoustiques liées à la dimension des tuyaux. À cet égard, un Traicté de l'Orgve publié à Paris chez Ballard en 1635 se trouve inséré dans l'Harmonie Universelle de Marin Mersenne (1636), faisant en sorte que les 300 dernières pages de cet ouvrage sont consacrées à la facture d'orgue. Si nous n'avons pu retrouver cet ouvrage dans ce qui subsiste du fonds ancien de la bibliothèque du Séminaire des Missions-Étrangères de Québec ou du collège des Jésuites, rien n'empêche de penser qu'il ait pu être présent dans la colonie.

\section{L'orgue À Québec Au TeMps de Mgr de LAVAL}

Il tombe sous le sens que la réalisation d'un orgue n'a pu être confiée à un ecclésiastique qui en ignorait complètement le jeu. À l'époque où Grouard est élève au séminaire, le personnel de la maison a compté parmi ses rangs nul autre que Louis Jolliet, futur découvreur du Mississipi. Né à Québec, entré au collège des Jésuites de la ville vers l'âge de onze ans, il est qualifié d'officier de musique dans le Journal des Jésuites. Tonsuré en 1662, Jolliet passe cinq ans au séminaire avant de quitter les ordres en 1667. C'est à Québec même que Jolliet a appris à toucher l'orgue sur l'instrument dont disposait la paroisse depuis au moins 1657, puis sur celui de 1663, apporté à Québec par Mgr de Laval et qui fut en usage dès l'année suivante.

Dans la chaine des transmissions des savoirs, nous serions porté à croire que le professeur d'orgue de Jolliet fut un ancien maîtrisien de la collégiale d'Ennezat en Auvergne, nommé François du Moussard ou Dumontsard, que l'on retrouve d'abord à ses côtés en 1665 au collège des Jésuites de Québec, puis au séminaire. Arrivé dans la colonie en tant que tambour du régiment de Carignan, son capitaine, l'avait libéré afin qu'il puisse poursuivre ses études vers la prêtrise. C'est d'abord «à raison qu'il estoit excellent musicien, mais avec dessein de luy faire la charité de le faire estudier» que Dumontsard fut reçu au collège des Jésuites à l'âge de 28 ans (Plante 2010). Suivant cette promesse, on l'admet au séminaire de Québec peu après. En 1668, Mgr de Laval lui confère les ordres mineurs. Il est donc au séminaire. Jusqu'à son retour en France en 1670, il touche l'orgue de Notre-Dame de Québec, comme le montrent les livres de compte de la paroisse qui lui verse un salaire pour ce service ${ }^{21}$. Les recherches menées par J.-F. Plante ont par ailleurs révélé que, peu après son retour en France, Dumontsard devient pour un temps maître de musique à la

21 «Payé au frère Joseph Boursier pour six mois de la pension du Sr du Moussard, $37^{\#} 10 \mathrm{~s}$. Et pour la moitié de son passage [et] le reconduire en son pays $34^{\#} 13$ sols, 4 ds le tout faisant $72^{\#} 3$ s. 4 ds. Ce qui luy avoit esté promis pour toucher les orgues» (Livres de comptes des marguilliers de N.-D.de-Québec, $\mathrm{CM}_{2} / \mathrm{C}_{1}$, 1, vol. 1, p. 15v, AAQ). 
collégiale d'Ennezat. Suivant le parcours alors assez commun du clerc musicien, il occupe par la suite le poste d'organiste à l'église paroissiale de Maringues en Auvergne (Plante 2010).

Tout comme Jolliet, Dumontsard exerce probablement une influence musicale sur son milieu, et plus particulièrement sur les chantres et musiciens de Québec, dont François d'Angers, Charles-Amador Martin, Germain Morin et Martin Boutet, tous élèves du collège des Jésuites de Québec. Si les quatre premiers reçoivent les ordres mineurs des mains de Mgr de Laval, deux d'entre eux, Martin et Morin, persévèrent vers la prêtrise. Boutet devient professeur de mathématique au collège de Québec, tout en étant chantre. Quant à Louis Jolliet, il finira sa vie comme professeur d'hydrographie au collège des Jésuites de cette ville. Considérant ce milieu particulièrement bien doté sous l'angle de la musique, on peut raisonnablement penser que François Grouard est initié jeune au jeu de l'orgue par l'un de ces officiers de musique du collège des Jésuites, et peut-être par Louis Jolliet lui-même qui agit comme organiste à la paroisse pendant quelques années (Vachon 2003). Un document qui remonte à 1720, nous apprend en effet que Jolliet « jouoit des orgues et avoit montré à en jouer à plusieurs personnes du Séminaire ${ }^{22}$ ».

Entré au séminaire en 1673 à l'âge de 11 ans, François Grouard est tonsuré et minoré le 3 avril 1683, puis élevé au sous-diaconat le 21 novembre suivant. Sans être prêtre, l'abbé Grouard porte néanmoins la soutane depuis qu'il est minoré. De ce fait, il jouit du respect et de la considération dus à son statut d'homme d'Église. Le 19 novembre de la même année, son beau-père le serrurier François Hurault et sa mère Marie Languille enregistrent son titre clérical chez le notaire François Genaple de Bellefonds afin de lui donner «moyen de vivre honnestement en la Profession Ecclesiastique ${ }^{23}$ ». Le même jour, dans l'une des salles du séminaire, Jean-François Buisson, dont le nom sera aussi rattaché à l'orgue, quoique dans une moindre importance, reçoit lui aussi son titre clérical. Le contrat signé par les parents de Grouard prévoit une rente annuelle de 75 livres tant qu'il persévérera dans la voie ecclésiastique qui doit le mener vers la prêtrise. En cas de changement d'orientation, le contrat sera considéré comme nul et sans effet, déchargeant dès lors les donateurs du devoir de payer cette rente.

Dès 1684, Mgr de Laval choisit Grouard pour occuper l'un des postes de chapelain au chapitre de Québec (Langevin 1874, 194). Tous les membres du chapitre, depuis les plus hautes dignités jusqu'aux enfants de chœur, doivent connaître le plain-chant. S'ils ne le savent pas, ils disposent d'une année pour l'apprendre ${ }^{24}$. Remplissant alors les fonctions dévolues au bas-chœur, c'est-à-dire le chant de l'office capitulaire, les chapelains sont au nombre de

22 Extrait des registres des délibérations de la Fabrique de Québec, collationné le 16 août 1746 et contenu dans le dossier relatif au procès opposant la veuve de Jean-Baptiste Bissot de Vincennes, demanderesse, au sieur de la Gorgendière, défendeur, au sujet du paiement et de la réservation d'un banc à N.-D.-de-Québec faits le 24 janvier 1656. 13 mars 1720-16 août 1746. BanQ, TL5, D1443.

23 Titre clérical de François Hurault et Marie Languille, son épouse, de la ville de Québec, épouse antérieure de Richard Grouard, pour François Grouard, son fils, 19 novembre 1683. Greffe de Genaple de Bellefonds, F. (1682-1709), BanQ, ZA41.

24 «Les statuts du chapitre de l'église cathedralle de Québec» [1687], CH-1-2a, p. 29v, 30, AAQ. 
quatre - dont François Grouard - et sont assistés par six enfants de chœur pour le chant de l'office capitulaire à la cathédrale. En raison de l'absentéisme chronique des chanoines retenus dans leurs multiples charges (cures, missions, etc.), le chant leur incombe plus qu'à quiconque dans le chapitre. Contrairement aux chapitres cathédraux de France, celui de Québec est uni au séminaire de Québec par une relation organique. Le séminaire fournit en effet la plupart des chanoines et des chantres du bas-chœur. Du reste, l'un des objectifs de départ du petit séminaire consiste à cultiver l'inclination des enfants pour l'état ecclésiastique en les exerçant notamment au service des autels et «en leur apprenant le plain-chant et les cérémonies ${ }^{25}$ ». Pour ce faire, le règlement du petit séminaire prévoit un exercice quotidien du plain-chant d'une durée d'une demi-heure ${ }^{26}$. Lors des dimanches et des fêtes inscrits au calendrier romain, tout le séminaire, directeurs, prêtres, clercs, pensionnaires et boursiers assurent alors le chant solennel de la messe et la psalmodie des heures canoniales à la cathédrale, apparaissant devant les fidèles en soutane, camail rouge, surplis et bonnet (Langevin 1874, 195; Baillargeon 1972, 245-46).

Sans cette collaboration du séminaire, dont certains membres occupent même des dignités au sein du chapitre, jamais l'évêque ni les chanoines n'auraient pu assurer de tels services liturgiques, compte tenu de la mince gratification annuelle accordée par la cour au siège épiscopal de Québec et à son chapitre. Dans un contexte de pauvreté endémique et de crises financières récurrentes, l'évêque, le chapitre et les Messieurs du séminaire tentent donc ensemble de résoudre au mieux la quadrature du cercle en faisant chanter gratuitement tous les garçons du petit et du grand séminaire ${ }^{27}$. Dans ses Mémoires sur la vie de Mgr de Laval, Bertrand de Latour écrit qu'une «soixantaine d'enfants de chœur fait un spectacle assez singulier. Ainsi, sans avoir de prébendiers en titre, le chapitre a un bas chœur fort considérable que le séminaire lui entretient» (Latour 1761, 96). Ainsi, depuis qu'il est entré au séminaire à l'âge de 11 ans en 1673, François Grouard évolue dans ce contexte liturgique où le chant d'église et la musique gagnent toujours en importance. Il n'étonne en rien que le séminaire de Québec ait voulu à son tour posséder un orgue pour sa chapelle. Du reste, l'orgue est on ne peut plus en faveur auprès du personnel enseignant et de certains pensionnaires qui apprennent à le toucher. C'est du moins ce dont témoigne le mouvement d'exaspération poussé par Mgr de Saint-Vallier en 1706, voulant qu'il n'y ait nulle émulation intellectuelle au séminaire et que les garçons qu'on y entretient n'y soient élevés que " $\mathrm{p}[\mathrm{ou}] \mathrm{r}$ estre menuisiers, sculpteurs, joueurs d'orgue \&c. mais non p[ou]r estudier ${ }^{28}$ ».

25 L'Abeille (séminaire de Québec) vol. 1, no. 26.

26 "Tres ancien Reglement du petit Séminaire de Québec» [s.d.], p. 100, 104, ASQ.

27 Sur les contorsions auxquelles plusieurs chapitres canoniaux de France se prêtent pour assurer le chant de l'office divin et l'exécution d'œuvres vocales en musique figurée par le bas-chœur sans pour autant se ruiner, voir l'article de Bernard Dompnier, «Descendre de leurs stalles pour entrer dans le chœur de musique: Les choriers, le plain-chant et la musique", dans Bernard Dompnier (dir.), Les langages du culte aux XXII ème et XVIII ème siècles, Presses universitaires Blaise-Pascal, Clermont-Ferrand, 2020, p. 315-336.

28 «Lettre de M. Tremblay à M. de Maizerets, 5 juin $1706 »$, Lettres O, no. 46, p. 22, ASQ. 
Un contexte d'efflorescence artistique, auquel l'orgue apporte sa contribution, existe bel et bien.

\section{DE LA FORTUNe DES INSTRUMENTS DE GRouARD}

Le premier instrument de Grouard disparut en fumée lors de l'incendie de la chapelle du séminaire en 1701. Habitués à disposer d'un instrument pour soutenir le chant des séminaristes, les directeurs de l'institution durent rapidement trouver un nouvel instrument pour répondre à leurs besoins. Aussi, estce sans doute pourquoi l'abbé Jean-François Buisson de Saint-Côme emprunta «une petitte orgue» au marchand bourgeois Sébille en 1703 (Gallat-Morin et Pinson 2003, 352) ${ }^{29}$. D'où provenait cet orgue, nous n'en savons rien. Selon le témoignage rendu par de Latour, l'ecclésiastique qui avait du génie pour la mécanique - François Grouard, pensons-nous - fabriqua plusieurs instruments pour les églises sur le modèle de l'instrument que Mgr de Laval avait fait installer dans sa cathédrale en 1664. De dimensions modestes, ces instruments étaient bien adaptés pour les chapelles conventuelles de la ville. À cet égard, beaucoup d'indices suggèrent que l'instrument qui fut acquis en 1705 par les Hospitalières de l'Hôpital général de Québec ait été l'un des opus de notre ecclésiastique organier.

Contrariées par les autorités qui voulaient plutôt confier la tenue du nouvel établissement à des filles séculières, les Hospitalières de l'Hôtel-Dieu de Québec finissent pourtant par rallier tous les suffrages grâce à l'habileté de leur supérieure, la Mère Louise Soumande de Saint-Augustin. Fille d'un maître taillandier de Québec, promise en mariage au fils d'un marchand de Blois en relations d'affaires avec des marchands de Québec, Louise Soumande est détournée de cette voie par son directeur spirituel, le jésuite Pierre Chastellain, qui la convainc de rompre avec le monde pour entrer chez les Hospitalières où elle prononce ses vœux en 1680. En raison d'éminentes qualités, la mère Soumande est choisie pour la fondation de l'Hôpital général dont elle devient supérieure en 1693. Son propre frère Louis, prêtre et agrégé au séminaire de Québec depuis 1692, est chargé cinq ans plus tard de rafraîchir et améliorer la chapelle de l'Hôpital général, ancienne propriété des Récollets. Nettoyée, embellie et ornée, l’ancienne chapelle des Récollets est désormais digne des mystères que l'on y célèbre, ce à quoi Mère Soumande de Saint-Augustin se montre particulièrement soigneuse, rapporte l'auteur de sa notice nécrologique.

Le 22 juillet 1704, lors de la messe et des vêpres solennelles de la fête de sainte Marie-Madeleine, l'une des patronnes de l'église de l'hôpital, une belle cérémonie «chanté[e] en musique 30 » réunit toute la haute société de Québec et de ses environs. Pour fêter les dix ans d'existence de l'institution, un clergé nombreux, tant du séminaire que des paroisses environnantes, entoure Mgr de Laval, dit Mgr l'Ancien, alors âgé de 81 ans. Cette cérémonie s'apparente à un geste politique de la part de la Mère Soumande, d'autant que les puissances séculières

29 L'abbé Buisson emprunte la «petitte orgue» du Sieur Tébut au marchand Jean Sébille.

30 Annales du Monastère de N.-D.-des-Anges, HG-A-13.14.1.2.1., vol. 2, p. 127, Archives de l'Hôpital général de Québec, AHGQ. 
sont également présentes à l'événement. Mais celui-là même qui devrait alors occuper la première place, Mgr de Saint-Vallier, considéré comme le fondateur de l'hôpital, est alors retenu en France pour les affaires du diocèse.

Ayant obtenu de Saint-Vallier le chapelain de son choix - fait plutôt rare à cette époque - la persuasive supérieure désire désormais doter la chapelle de son hôpital d'un orgue pouvant soutenir le chant des religieuses ${ }^{31}$. Les annales de l'Hôpital général rapportent que la Mère Soumande eut connaissance qu'un petit orgue se trouvait au palais épiscopal. Comme elle «sçavoit si bien s'insinuer dans les esprits et persuader qu'elle venoit à bout de tout ce qu'elle entreprenoit ${ }^{32}$, la Mère Soumande obtint ce qu'elle désirait. À la lecture de ce passage des annales de l'Hôpital général, plusieurs questions surgissent. Comment la Mère Soumande eut-elle connaissance de l'existence de cet instrument au palais épiscopal? Pourquoi un orgue s'y trouvait-il ? Pour quelle raison s'eston départi aussi facilement d'une telle pièce de mobilier liturgique?

Les liens familiaux furent sans doute le levier le plus puissant. Grand bienfaiteur de l'école de Saint-Joachim, déjà nommé chanoine en 1685, l'abbé Louis Soumande, frère de la mère Soumande de Saint-Augustin, connaissait évidemment cet instrument qui devait se trouver dans la chapelle du palais épiscopal. Sans grand risque d'erreur, on peut penser que ce sont les abbés Soumande et Leblond de Latour qui coordonnèrent les travaux de décoration de la chapelle du palais épiscopal de Mgr de Saint-Vallier avec des séminaristes, comme cela s'était produit pour la chapelle du séminaire ${ }^{33}$. Le petit orgue en question devait être au jubé de ladite chapelle (fig. 2) qui, toujours en chantier lorsque Bacqueville de La Potherie la visita en 1700 , promettait pourtant d'être magnifique par ses dedans et par «son retable d'Autel, dont les Ornemens sont un raccourci du celui du Val de Grâce» (Bacqueville 1753, 234-35). À l'exemple du magnifique baldaquin — aujourd'hui dans l'église de Neuville (Porter 1982) —, il est peu probable que l'orgue n'ait pas été lui aussi une production locale, d'autant que l'instrument était de petite dimension, selon l'annaliste de l'Hôpital général. Suivant tout ce qui a été exposé jusqu'ici, l'ecclésiastique ayant fait de petits orgues pour diverses églises, selon Latour, pourrait fort bien être le créateur de cet instrument installé dans la chapelle du palais épiscopal.

En l'absence de Saint-Vallier toujours retenu en France, les occupants du palais épiscopal se succèdent. D’abord, Mgr de Laval et sa suite. À la suite de l'incendie du séminaire de 1701, ils y élisent temporairement domicile et y

${ }^{31}$ Cette ancienne paroissienne de Notre-Dame de Québec connaît très bien l'importance du chant et de la musique d'église dans la solennisation du culte. La lettre circulaire envoyée à la maison de Dieppe au lendemain de sa mort survenue en 1708 rapporte combien le chant grégorien lui tenait à cœur. AHGQ, Lettres circulaires.

32 HG-A-13.14.1.2.1., vol. 2, p. 127, AHGQ.

33 En 1698, «ils eurent la permission d'agréger M. Leblond, jeune prêtre qui manifestait de grands talents pour la sculpture et l'architecture. C'était un sujet précieux pour Mgr de Laval qui n'épargnait rien dès qu'il s'agissait de contribuer à la splendeur du culte de Dieu et à l'ornement des églises et des autels. Le pieux prélat fit venir cette année des outils de sculpture et M. Leblond [ ... ] s'occupa de former des élèves. C'est ainsi que la religion et la piété favorisèrent toujours les arts». Elzéar-Alexandre Taschereau, Histoire du Séminaire de Québec, manuscrit n. d., Bibliothèque et Archives Canada, MG 17, A3, vol. 345, fol. 5561; Claude Payer et Daniel Drouin, Les tabernacles du Québec des XVII ème et XVIIİème siècles, Québec, Les Publications du Québec, 2016 


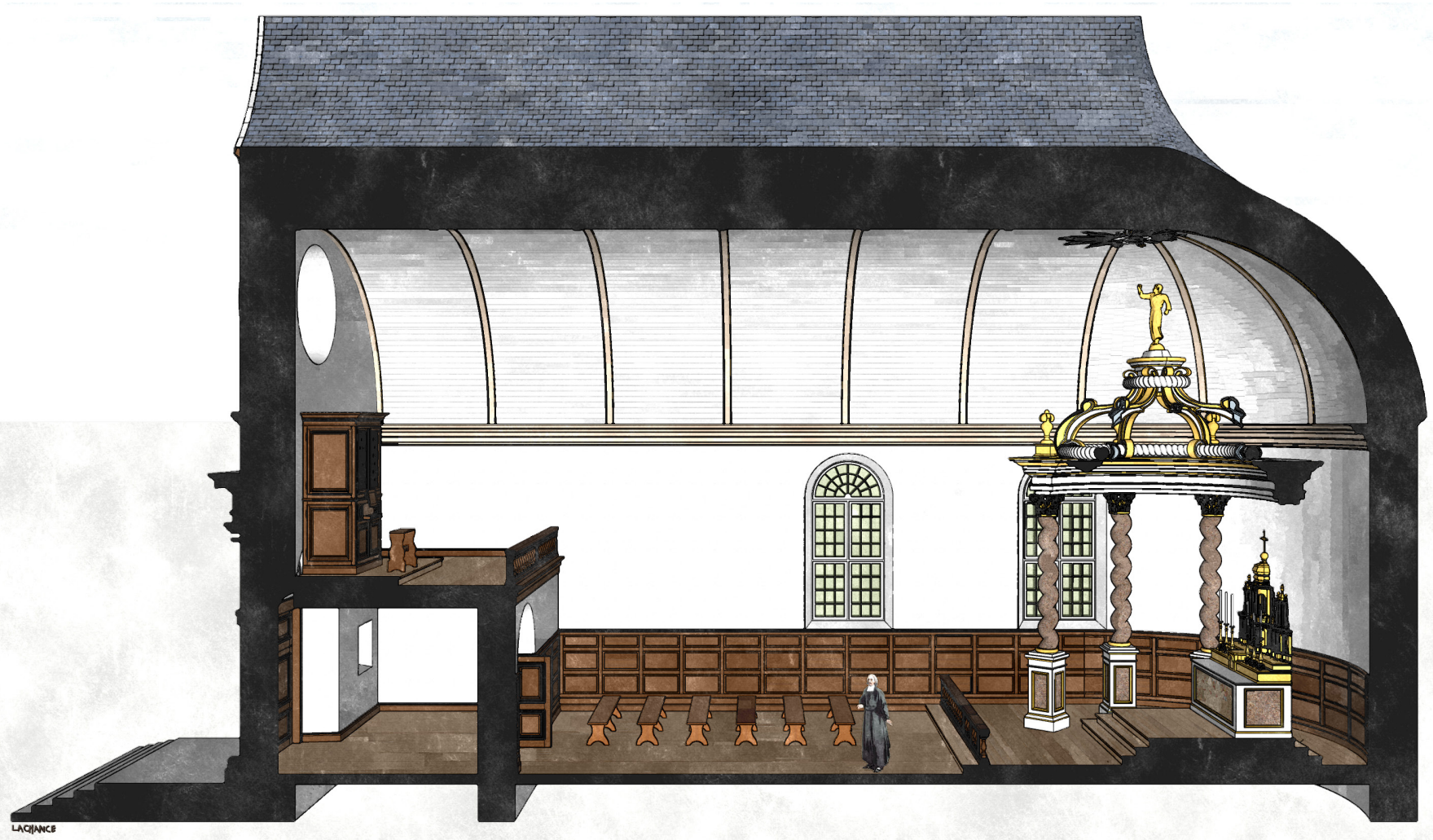

Figure 2. Coupe longitudinale de la chapelle du palais épiscopal avec l'orgue à la tribune, ca 1700. 
demeurent jusqu'en avril 1704. En théorie, Saint-Vallier qui doit regagner Québec en cette même année doit reprendre possession de sa demeure épiscopale. Mais, en pleine guerre de la Succession d'Espagne, le navire qui le ramène à Québec est pris par les Anglais. S’ensuit une longue captivité de l'évêque de Québec en Angleterre. Toujours libre, le palais épiscopal voit s'y installer les intendants Beauharnois et Raudot, dont la résidence de fonction est à son tour la proie des flammes en 1705 (Têtu 1896, 37-38) ${ }^{34}$. À cette date, seule la moitié du bâtiment conçu par Claude Baillif et la chapelle sont vraiment terminés (Charlevoix 1744, 107). Tout est là, pour que débute le démeublement de ce lieu de culte magnifique certes, mais ayant désormais perdu son utilité première.

Comme le souligne l'annaliste de l'institution, on voyait le prélat « dégarnir son Palais épiscopal [...] des meubles, linges et ustencilles pour en garnir son hôpital35». Et c'est peut-être pourquoi les annales de l'Hôpital général de Québec rapportent qu'il était bien facile d'obtenir cet instrument, alors à l'évêché. Dans le contexte de ces années d'absence de Mgr de Saint-Vallier, sa générosité envers l'Hôpital général s'est inévitablement exercée par personnes interposées, notamment par l'abbé de Maizerets, vicaire-général et supérieur ecclésiastique de l'Hôpital général en l'absence de l'évêque. À l'évidence, l'instrument n'a pas été acheté mais tout simplement gracieusement offert en 1705. Musicien à ses heures et ayant des musiciens dans son entourage, Raudot qui loge désormais au palais épiscopal ne peut qu'être sensible aux vues de la supérieure qui lorgne le petit instrument.

L’orgue est installé au jubé que la Mère Soumande fait construire dans la chapelle de l'hôpital pour le recevoir, disent les annales. Encore faut-il trouver quelqu'un qui puisse en jouer. La supérieure jette alors son dévolu sur l'aumônier de l'Hôpital général qui, manifestement, connait déjà la musique ${ }^{36}$. Sur les instances de la supérieure, l'abbé Daniel-Guillaume Serré de la Colombière apprend à toucher l'orgue auprès d'un maître qui est alors à Québec et qui montre «à jouer du clavessin 37 ». Apprendre à toucher l'orgue sur un clavecin est alors fréquent puisque le jeu de cet instrument ne requiert pas les services d'un souffleur. À cette date, les clavecins ne sont cependant pas légion à Québec. Grâce aux recherches menées par Élisabeth Gallat-Morin, nous savons que René-Louis Chartier de Lotbinière, l'un des directeurs de l'hôpital général nommé par Mgr de Saint-Vallier dès la fondation de l'institution, possède une épinette, comme le montre l'inventaire de ses biens dressé lors de son remariage en 1701 (Vachon 1968; Gallat-Morin et Pinson 2003, 329-30 et 356-60). Considérant les besoins de l'aumônier, l'instrument a pu lui être prêté afin qu'il

34 À la suite de l'incendie du palais de l'intendance en 1713, l'intendant Bégon s'était transporté avec sa famille au palais épiscopal. À son retour dans la colonie la même année, Mgr de Saint-Vallier avait préféré se retirer parmi les pauvres de son hôpital et laisser le palais à l'intendant.

35 Annales du Monastère de N.-D.-des-Anges, HG-A-13.14.1.2.1, vol. 2, p. 11, AHGQ.

${ }^{36}$ Les recherches menées par Élisabeth Gallat-Morin révèlent que l'abbé Daniel-Guillaume Serré de La Colombière possédait un dessus et une basse de viole ainsi que les pièces de clavecin de Chambonnières. Il était donc déjà musicien au moment où il prit des leçons de clavecin.

37 HG-A-13.14.1.2.1, vol. 1, p. 137, AHGQ. 
puisse s'exercer ${ }^{3}$. L'identité de ce maître, tout comme celle de l'ecclésiastique organier, a intrigué Élisabeth Gallat-Morin qui n'est pas parvenue à percer ce mystère.

Qui donc vers 1705 était en mesure de comprendre suffisamment l'orgue pour pouvoir accorder l'instrument de l'hôpital général? Qui donc était ce maître de musique auquel l'annaliste de l'Hôpital général fait allusion? Comme le fait remarquer Gallat-Morin, Louis Jolliet (1645-1700) est mort à cette date tandis que les organistes connus de Notre-Dame de Québec ne sont pas encore apparus, dont le premier, François Hérault, sieur de Saint-Michel-Gourville, n'entre au service de la cathédrale qu'en 1721. Voilà qui nous place une fois de plus face à un vide documentaire. L'intendant Raudot a bien quelques musiciens amateurs autour de lui mais rien n'autorise pour autant à penser que l'aumônier de l'hôpital puisse avoir bénéficié de l'enseignement d'un maître au palais de l'intendance. Les livres de comptes de l'hôpital qui inscrivent toutes les dépenses, jusqu'aux quelques sols versés à un petit garçon pour avoir gardé les vaches, ne rapportent aucun paiement pour des leçons de clavecin à un quelconque maître. À ce moment, le seul ecclésiastique de Québec dont le nom est accompagné du titre de maître dans les documents administratifs est François Grouard. En effet, dans l'acte de démission du curé de Champlain, le 18 mai 1687, Grouard est désigné comme étant «Maistre François Grouard sousdiacre39». Serait-ce le maître en question qui montra à l'abbé de La Colombière-Serré? On ne peut raisonnablement écarter cette hypothèse considérant la proximité de toutes les personnes dont il a été jusqu'ici question.

\section{François Grouard, MAîtTRE DISCRET}

Dans les bas-chœurs de France, le maître du chant est le Magister Musicae. L'exemple français peut ici nous être d'un grand secours pour comprendre ce que représente alors ce titre. Reportons-nous à Tours au XVII ${ }^{\text {ème }}$ siècle. Depuis 1634, les moniales bénédictines de l'abbaye de Beaumont-lès-Tours reçoivent des leçons de chant de Charles Mauret, maître de musique de la psallette de l'église collégiale de Saint-Martin de Tours, puis de Charles Des Hayes, tous deux ecclésiastiques ${ }^{40}$. Placée sous la juridiction du chapitre de l'église collégiale de Saint-Martin de Tours, l'abbaye de Beaumont doit en vertu d'une très ancienne convention entretenir certains "petits chappellains» de la collégiale de Tours. Outre ces nombreux chapelains, cette dernière compte parmi ses effectifs un maître de musique et un organiste. La présence épisodique à l'abbaye de l'abbé Mauret, Magister musicae de la psallette de l'église collégiale Saint-Martin de Tours s'explique par l'importance des liens de tous ordres qui unissent les deux institutions. L'enseignement musical dispensé aux professes

38 Ayant appris assez rapidement à toucher l'orgue, l'abbé de La Colombière put s'exécuter à tous les dimanches et fêtes sur le nouvel instrument installé au jubé de la chapelle. AHGQ, HG-A13.14.1.2.1, vol. 1, p. 137.

39 Paroisse de Québec, no. 18, AAQ.

40 Sur ces liens, voir: "Traité de la police ecclésiastique», Les auvres de Maître René Choppin, Paris, D’Allain, 1662, vol. 4, p. 306; Défense des privilèges de la noble et insigne église de Saint-Martin de Tours, Paris, 1708, p. 115; Le Paradis délicieux de Latouraine, Paris, Louys de La Fosse, 1661, p. 41. 
et aux novices de l'abbaye de Beaumont doit se rapprocher de celui dispensé aux enfants de la psallette de Saint-Martin-de-Tours ${ }^{41}$. À cet égard, le Magister Musicae enseigne aux religieuses le plain-chant qui constitue alors l'essentiel du chant de l'office divin mais aussi la polyphonie simple ${ }^{42}$. Dans certains contextes, cette fonction de maitre de musique dans le bas-chœur implique également une capacité à toucher l'orgue. Pour prendre l'exemple déjà cité de François Du Moussard ou Dumontsard, le recensement de Québec de 1666, le qualifie de "Mr [maître] de Musique ${ }^{43}$ », parce qu'il occupe la fonction de chantre principal et de responsable de la musique, autant au collège des Jésuites de cette ville qu'à la paroisse. Peu après son retour en France en $1670^{44}, \mathrm{Du}$ monsard, dont l'activité d'organiste est documentée autant pour la colonie que pour la France, agit toujours à titre de maître de musique à la collégiale SaintVictor et Sainte-Couronne d'Ennezat ${ }^{45}$. Comme l'explique Bernard Dompnier, le statut de maître de musique ne s'acquiert habituellement qu'au terme d'un parcours qui débute dans l'enfance, alors que le garçon évolue dans le bas-chœur de l'église à laquelle il est rattaché ${ }^{46}$. Dumonsard illustre bien cette ascension depuis la maittrise vers la charge de maître de musique. N'en serait-il pas de même pour Grouard que l'on qualifie de «maître»?

Ce dernier est chapelain au chapitre de Québec et s'occupe de facto du chant dans le bas-chœur. Son activité d'organier amateur - qui constitue ici l'essentiel de l'hypothèse que nous formulons dans cet article - est presqu'indissociable d'une capacité à toucher cet instrument, surtout dans le contexte du séminaire où l'enseignement de cet instrument est également documenté47. Or, ce maitre de musique - dont une fois de plus on tait curieusement le nom ne serait-il pas ce maître François Grouard dont l'acte de décès, en date du 29 novembre 1743, indique "[qu']est décédé Maître François Grouard, sousdiacre et chapelein du chapitre de la cathédrale de Québec, âgé de 81 ans»? Jusqu'à preuve du contraire, seul François Grouard jouit du titre maître parmi

41 Monsieur Charles Des Hayes a succédé à Monsieur Mauret en tant que maître de chapelle à l'abbaye. En 1652, Monsieur Des Hayes était curé de Beaumont-la-Ronce et qualifié de «maistre de musique». Voir: "Chronique de l'abbaye de Beaumont-les-Tours", Mémoire de la Société archéologique de Touraine, vol. 26, 1877, p. 168; Olivier Marcault, «Les psallettes dans le diocèse de Tours avant la Révolution», Bulletin de la Société archéologique de Touraine, tome XXVIII, 1912, p. 255-256.

42 L'analyste de l'abbaye écrit que les leçons de Monsieur Mauret profitèrent si bien aux moniales qu'elles purent désormais chanter à «quatre parties». Voir les listes d'œuvres vocales en usage à Rouen dans l'ouvrage de Armand Collette et Adolphe Bourdon, Histoire de la mâtrise de Rouen, première partie, depuis les origines jusqu'à la Révolution, deuxième partie, depuis la Révolution jusqu'à nos jours, Rouen: Cagniard, 1892, p. 67-68.

43 Recensement du Canada, 1666. Centre des archives d'outre-mer (France), vol. 460.

44 Livres de comptes de N.-D.-de-Québec, $\mathrm{CM}_{2} / \mathrm{C}_{1}$, 1, vol. 1, p. 15v, AAQ.

45 Archives départementales du Puy-de-Dôme, Chapitre de la collégiale Saint-Victor et SainteCouronne d'Ennezat, Actes capitulaires, registre 1672-1680 (AD 63, 18 G 8), citées Plante (2010, 202).

46 "Quelle que soit la diversité de leur déroulement, les carrières commencent à peu près toutes de la même manière et les profils des maîtres sont très proches au moment où ils accèdent à leur premier poste. Il s'agit d'hommes jeunes qui, après avoir eux-mêmes été formés dans une maîtrise, ont ensuite passé quelques années sans s'éloigner de celle-ci, participant au chant des offices au sein du bas chœur et continuant sans doute à se perfectionner en composition dans l'ombre du maître» (Dompnier 2017, à paraître).

47 Extrait des registres des délibérations de la Fabrique de Québec. BanQ, TL5, D1443. 
les ecclésiastiques de Québec. Il pourrait donc avoir été celui qui a enseigné à l'abbé Serré de la Colombière. Pourquoi un tel mystère autour de Grouard? Telle est la question dont la réponse va clore cet article.

\section{La faute de Monsieur Grouard}

Sa vie durant, François Grouard reste sous-diacre, donc «ecclésiastique», au sens où ce terme sert à désigner globalement les clercs non-prêtres parmi lesquels on range les clercs minorés, sous-diacres et diacres. C'est d'ailleurs sous ce titre «[d']ecclésiastique» qu'il est désigné dans le contrat de mariage de sa demi-sœur en décembre $1685^{48}$. Ce détail est d'importance car Latour a délibérément choisi ce terme pour désigner le clerc facteur d'orgue de Québec, sans pour autant le nommer. Mais justement, pourquoi ne pas avoir nommé Grouard alors que l'auteur des mémoires sur la vie de Mgr de Laval parle nommément de prêtres et de dévots, tels les Sieurs «Gaston \& Courrier» ou encore Yves Le Riche, dont l'histoire n'a pratiquement conservé aucun souvenir (Latour 1761, 101) ? Oubli involontaire de la part du mémorialiste de Mgr de Laval? Cela est peu probable quand on songe que Latour a disposé d'une vaste collection de documents, de mémoires et d'informations très précises qui lui ont permis de dresser une chronique détaillée des événements ayant marqués l'épiscopat de Mgr de Laval et de son successeur. Le mystère plane.

Les sources capitulaires sont peu loquaces sur les années qui suivent l'entrée de François Grouard au chapitre de Québec. La signature de ce dernier figure occasionnellement dans les registres, mais sans plus. Par ailleurs, les relations de François Grouard avec les directeurs du séminaire de Québec se détériorent vers le milieu de la décennie 1690 au point qu'il doit quitter le séminaire où il n'est toujours que pensionnaire et non agrégé au corps ecclésiastique des Messieurs du Séminaire, sorte de communauté de vie apostolique réunissant des prêtres séculiers (Lafontaine 1981, 3). N'ayant plus de quoi vivre ou si peu, François Grouard tombe à la charge de sa famille. C'est sans doute la raison pour laquelle son frère Jacques Grouard et son beau-frère Nicolas Rousselot de Laprairie, tous deux réputés bourgeois de Québec, présentent une requête en faveur de leur parent à l'intendant Beauharnois en vue de réclamer du séminaire une pension pour leur frère, prétendument devenu infirme.

Rejetant les prétentions de la famille, les directeurs du séminaire contrattaquent en 1703, en rappelant que François Grouard a été éjecté de l'institution, non pas tant en raison de ses infirmités comme le soutient la partie adverse, mais bien "parce qu'il ne se comportait pas comme un ecclésiastique doit se comporter et citent mêmes quelques-unes de ses actions qu'ils disent être de notoriété publique 49 ». Qu'est-ce à dire? S'agit-il d'une question d'insubordination ou de paresse ou encore, de mœurs répréhensibles? Les statuts du chapitre dressés en 1687 par Mgr de Laval rappellent que parmi tous les chapelains

48 Registres des insinuations de la Prévôté de Québec, vol. 1, $1^{\mathrm{er}}$ mars 1667-25 septembre 1696, p. $515-520$

49 Requête de Rousselot et Grouard à François de Beauharnois, ASQ, séminaire 5, no. 76; ASQ 34 , no. 134 . 
destinés à chanter l'office, le maître de psallette qui s'occupe des enfants de chœur doit avoir passé quelque temps dans l'ordre clérical et être d'une probité morale reconnue, autant sur le plan de la doctrine que des mœurs. On ne saurait être plus clair à ce sujet: "on ne souffrira jamais aucun, parmy ceux de la Compagnie qui, donnant par sa conduitte un veritable fondement a tels bruits scandaleux, ne voudroit pas s'en deporter ${ }^{50} \%$. Comme l'indique le titre de «maître» qui précède le nom de François Grouard dans quelques documents, il est maître de psallette au chapitre de Québec.

Soit par pudibonderie, par discrétion ecclésiastique ou par déférence pour les familles impliquées, tous les documents demeurent laconiques sur cette affaire. Puisque personne ne veut alors parler ouvertement de ce que l'on reproche à notre homme, ni les directeurs du séminaire, ni même l'intendant devant qui la cause est portée, on peut donc en conclure qu'il existe un tabou autour de la faute de l'abbé Grouard, tabou dont ni la paresse ni l'insubordination, ni même le larcin ne se seraient vus entourées dans les documents. Quelque chose de plus grave est reprochée à notre ecclésiastique. Monsieur Glandelet, justement l'un des directeurs du séminaire qui a refusé le retour de Grouard dans les murs de l'institution, fait alors montre d'une morale sourcilleuse. Une lettre de ce dernier à Mgr de Saint-Vallier, nous apprend qu'une personne de distinction, bien au fait de tous les potins de la petite société québécoise, les lui rapporte fidèlement afin de le tenir informé de toutes les entraves à la pureté commises dans la ville de Québec ${ }^{51}$. Sans être dénué de vraisemblance, un tel motif de renvoi ne semble pas correspondre pleinement à la situation de Grouard. Du moins, nous n'en avons strictement trouvé aucune preuve documentaire. Un autre motif peut expliquer ce renvoi: la volonté d'assainir les finances du séminaire, opération rendue nécessaire par la pauvreté croissante de l'institution dans un contexte de misère générale de la Nouvelle-France provoqué par la dévaluation de la livre tournois depuis 1683 .

\section{FAIblesse ET COUARDISE AU SÉMINAIRE : GROUARD ET SES SEMBLABLES}

C'est en 1692 qu'apparait pour la dernière fois la signature de Grouard dans les actes capitulaires du chapitre de la cathédrale de Québec, l'année même où Mgr de Saint-Vallier dénonce la fainéantise de certains ecclésiastiques. SaintVallier est alors dans l'obligation de rappeler aux directeurs qu'il n'appartient qu'à l'évêque de permettre à un ecclésiastique de demeurer au séminaire, fut-il chanoine! De même, est-il défendu aux directeurs d'agréger quiconque sans sa permission. De plus, les prêtres et les clercs du séminaire qui se voient dispensés des missions de la campagne pour cause d'infirmité, doivent impérativement

50 «Les statuts du chapitre de l'église cathedralle de Québec, 1687», CH-1-2a, p. 26, 29v, 30, 30v, 38, AAQ.

51 L'abbé Glandelet informe Mgr de Saint-Vallier que «les désordres d'impureté sont si fréquents et si familiers qu'on n'en fait plus un mistaire; rien n'est si commun que de voir des filles grosses et une personne de distinction qui connoit fort bien tout ce qui se passe dans Québec me disoit il y a peu de jours que la moitié de Québec estoit un franc bordel». "Lettre de l'abbé de Glandelet, vicaire général, à Mgr de SaintVallier, prisonnier en Angleterre, Québec, 1706» (Lettres P, no. 9, ASQ). 
disposer d'un titre clérical suffisant pour permettre de pourvoir à leurs besoins et n'être pas à la charge du séminaire ${ }^{52}$. Enfin, il est inadmissible pour l'évêque que plusieurs séminaristes et clercs ayant reçu les ordres majeurs (sous-diaconat, diaconat et sacerdoce) cherchent le confort et la sécurité de la vie au séminaire - alors l'un des plus beaux bâtiments de Québec - plutôt qu'embrasser la vie de renoncement à soi-même qu'impose le ministère dans les missions et les cures d'un pays de colonisation ${ }^{53}$. Devant le refus de certains prêtres de prendre en charge des cures ingrates en pays de colonisation, telles que celle de Mont-Louis en Gaspésie, le Séminaire de Paris insiste sur l'importance d'inculquer l'esprit de sacrifice aux enfants de la petite école du séminaire de Québec afin «de former dès l'enfance de bons sujets qui par vertu soient disposés à tout ${ }^{54}$ ». Du côté du chapitre, les statuts dressés en 1687 par Mgr de Laval stipulent pour leur part que les chapelains, habituellement des clercs minorés et des sous-diacres, doivent prendre les ordres sacrés dès qu'ils le pourront, ne pouvant rester indéfiniment dans ce statut d'entre-deux que ne peut supporter une colonie aussi pauvre. Le sacerdoce étant presqu'une obligation dans cette Nouvelle-France qui manque de prêtres, tous doivent y tendre au séminaire 55 .

À cela s'ajoute que la situation financière du séminaire se révèle terriblement difficile en ces années. Les dettes s'accumulent, provoquant l'impatience des créanciers. En 1699, les directeurs en avisent Mgr de Laval. Ils lui rappellent que «Mr Buisson est à bout de toutes ses industries pour trouver de l'argent. Il se présente tous les jours des payments à faire ${ }^{56} \%$. Deux ans plus tard, loin de s'améliorer, la situation se détériore. L'incendie de 1701 cause de dommages s'élevant à plus de 30000 livres. Puis, celui de 1705 complique encore davantage la situation financière. De 57 écoliers, leur nombre du petit séminaire passe à 12 . Il faut rationnaliser les dépenses. Les clercs sans utilité véritable ou incapables de s'acquitter de leurs devoirs font les frais de ces coupes sombres. Ainsi, le séminaire n'a plus les moyens d'entretenir des ecclésiastiques qui n'aspirent pas au sacerdoce ou ne peuvent y accéder, faute de talent, de santé ou de volonté. À une époque où l'on entend corriger la situation, la conception familiale et rassembleuse du séminaire, telle que la nourrissait Mgr de Laval, n'est plus. Devant l'urgence de redresser les finances de l'institution, le dévouement de jadis de ces clercs non ordonnés n'a pas plus beaucoup de valeur. Encore en 1705, on insiste sur l'importance de ne pas recevoir d'ecclésiastiques inutiles ${ }^{57}$.

Le plaidoyer de la famille Hurault-Grouard contient quelques détails intéressants sur le parcours de Grouard. Ce dernier a été recruté par Mgr de Laval et les directeurs du Séminaire alors qu'il n'avait que sept ans. Il a été élevé

52 «Lettre de l'évêque de Québec aux supérieurs, directeurs et autres ecclésiastiques du Séminaire épiscopal de Québec, 11 février 1692 ». MG1-C11 ${ }^{\mathrm{A}}$, vol. 35, fol. 257v-259v.

53 Ibid.

54 «Lettre des abbés Louis Tiberge et Jacques de Brisacier aux messieurs du Séminaire de Québec, 23 mai $1702 »$. Lettres M, no. 28, ASQ.

55 «Les statuts du chapitre de l'église cathedralle de Québec, 1687», CH-1-2a, p. 30, 38, AAQ.

56 «Lettre collective à Mgr de Laval sur l'état financier du séminaire, 9 avril 1699 ». ASQ, Lettres N, no. 125 .

57 «Mémoire sur l'état du Roy apellé des charges indispensables du Canada, 7 mai 1705». BACMG1-C ${ }^{11} \mathrm{~A}$, vol. 23, fol. 24-27. 
aux quatre mineurs (portier, lecteur, exorciste et acolyte) et au premier majeur (sous-diaconat), d'où son titre "[d']ecclésiastique». Sous-diacre, probablement employé à bien d'autres fonctions que le chant de l'office divin qui incombe à sa charge de chapelain au chapitre, il se serait usé à la tâche, selon les siens. Devenu infirme "par les services qu'il [...] a rendus» au séminaire, Grouard s'en voit maintenant congédié sans qu'aucune compensation ne lui soit versée. Expulsé peu avant $1696^{58}$, Grouard n'est pas un cas exceptionnel à cette époque. Un de ses contemporains connait un sort semblable. Jacques Lamarche, fils d'Urbain Baudry dit Lamarche et de Madeleine Boucher, des Trois-Rivières, entre au petit séminaire à l'âge de 10 ans le 9 novembre $1685^{59}$. Bien qu'étant le neveu de Pierre Boucher, déjà fort estimé dans la colonie, les directeurs ne peuvent le garder car «n'ayant pu réussir aux études ${ }^{60}$ ». En 1688, La Marche, déjà considéré clerc au recensement, retourne chez ses parents. Mais, le 26 mars 1697 , ayant désormais plus de 20 ans, il est réadmis au séminaire "[puisqu'] ayant quelque commencement de latin ${ }^{61}{ }$. Dès le 10 octobre de la même année, il est tonsuré. Ne pouvant réussir dans ses études, ce clerc minoré va devoir quitter l'institution. Solution de compromis, «sa mère le donna entièrement au séminaire ${ }^{62} »$. La Marche est relégué au rang de domestique du séminaire. La chute est brutale. Le ressentiment naît. En 1706, il passe en France. À Paris, il gagne un petit pécule comme chantre à l'église Saint-André-des-Arts, ce qui atteste ici combien l'étude du plain-chant est prise au sérieux au séminaire de Québec ${ }^{63}$. Amer face à ses échecs successifs et au traitement injuste dont il fait désormais l'objet après avoir "passé près de dix ans au service des Mrs du Séminaire sans aucun salaire que sa nourriture et entretien ${ }^{64}$ », La Marche ne se gêne pas pour dénoncer ses maîtres d'hier à Pontchartrain en 1713, les accusant «de commettre toutes sortes d'injustices quand il s'agit de leur intérêt $t^{65}$ ». À maints égards, son profil ressemble à celui de Grouard. Au demeurant, son expulsion du séminaire se produit au cours des mêmes années où les directeurs tentent de se débarrasser de Grouard. En 1707, l’abbé Tremblay écrit à propos de Jacques La Marche: «Vous êtes bienheureux d'en estre defait ${ }^{66}$ ». Les propos sur Grouard ne sont pas moins durs.

Sous-diacre depuis 1683, Grouard n’a pas encore accédé à la prêtrise. Âgé de trente ans en 1692, rien n'augure un changement de statut. Pourtant, certains sujets du séminaire qui n’ont même pas encore été revêtus du sacerdoce se voient déjà envoyés dans les missions du séminaire pour y apprendre le métier

58 «Lettre de M. Thiberge à M. de Bernières, sup. du Séminaire de Québec, Paris, 13 juin 1696 », Lettre O, no. 17, ASQ.

59 La Revue de l'Université Laval, vol. 11, 1957, p. 743-750.

60 Annales, ms. 2a, p. 14, ASQ.

61 Annales, ms. 2a, p. 24, ASQ.

62 Henri-François Gravé de La Rive, Transcripta, 1786, Séminaire 13, ms. 6, p. 5, ASQ.

63 La Revue de l'Université Laval, vol. 11, 1957, p. 743-750.

64 Mémoire de [Jacques La Marche] à Mgr le Comte de Pontchartrain [1713], Chapitre, III-3, AAQ.

65 En 1724, il est toujours à Paris. Mémoire de [Jacques La Marche] à Mgr le Comte de Pontchartrain, 1713. Chapitre, III-3, AAQ; La Revue de l'Université Laval, vol. 11, 1957, p. 743-750.

66 «Lettre de l’abbé Henri-Jean Tremblay aux Messieurs du Séminaire de Québec, Paris, 18 juin 1707 ", Lettres M, no. 38, p. 42, ASQ. 
de missionnaire et se faire peu à peu à la langue de leurs futures ouailles, tels ce Pierre Thierry, entré au grand séminaire en $1674^{67}$, soit un an après Grouard ou encore Jacques-Alexis Fleury Deschambault qui, «étant sous-diacre fut appliqué aux missions des Sauvages de l'Acadie avec Mr Thierry ${ }^{68}$ ». Soit par manque de dispositions pour l'étude ou d'inclination pour le ministère sacerdotal, ou encore par infirmité contractée au cours de sa formation, Grouard ne semble jamais avoir été pressenti pour une telle tâche, ou n'y a jamais consenti par goût.

À tort ou à raison, on ne peut par ailleurs s'empêcher d'établir une corrélation entre le renvoi de Grouard et l'arrivée au séminaire d'un autre individu beaucoup plus prometteur. Jacques Leblond de Latour débarque à Québec sur l'invitation de Mgr de Laval. Provenant d'une famille réputée de peintres, de sculpteurs et d'architectes de Bordeaux, Leblond de Latour enseigne la sculpture aux élèves du séminaire dès son arrivée, tout en poursuivant sa formation ecclésiastique. Il prend la soutane et le rabat en 1696, année où Grouard vient tout juste de quitter le séminaire. Deux ans plus tard, il y est agrégé comme "ecclésiastique», honneur et sécurité que les directeurs de l'institution ont refusés à Grouard. Du reste, Leblond promet bien davantage que Grouard en raison de l'étendue de ses talents à une heure où, justement en 1698, il est encore question de reconstruire la cathédrale ${ }^{69}$.

En juin 1696, le Séminaire des Missions-Étrangères de Paris rassure la filiale de Québec en lui précisant que rien ne laisse présager un retour de Grouard au séminaire, voire une éventuelle poursuite en justice de sa part ${ }^{70}$. À l'évidence, Grouard est à Québec, peut-être chez son frère Jacques Grouard. L'ayant désormais sur les bras, la famille cherche à se soulager d'un tel fardeau. Pour ce faire, François Hurault s'adresse à l'abbé Tremblay, procureur du Séminaire de Québec à Paris. Dans une lettre d'août 1696 où il est question de Grouard, on peut lire que, malgré qu'il ait "trouvé un lieu pour le placer» en France, François Hurault est fâché que l'on ne se soit pas occupé de faire passer François sur le

\footnotetext{
67 Annales, ms-2a, p. 4, ASQ.
}

68 Annales, ms-2a, p. 8, 11, ASQ.

69 Dans son histoire du séminaire de Québec restée manuscrite, Mgr Taschereau écrit pour l'année 1698: "Si l'on en eût les moyens, on se fut mis en frais de bâtir une nouvelle cathédrale et l'on avait même jeté les yeux sur Mr Leblond pour en diriger la construction et la décoration. Mais l'Évêque, le chapitre et la Fabrique avaient si peu de ressources disponibles que l'on n'aurait pas été capable de former une somme de 4000\# pour acheter un orgue comme on le désirait». En 2004, nous avions suggéré à Élisabeth Gallat-Morin que l'ecclésiastique qui fabriquait des orgues pouvait être l'abbé Jacques Leblond de Latour. Arrivé à Québec en 1690, ce dernier fut immédiatement employé par Mgr de Laval aux travaux d'architecture et de sculpture. Devenu ecclésiastique en 1696, il continua à s'occuper de sculpture et contribua activement à décorer la chapelle du séminaire, tout en enseignant aux garçons du petit séminaire. En 1706, il fut ordonné prêtre et nommé curé à la Baie Saint-Paul. De 1712 à 1714, il fut chanoine au chapitre de Québec. À la lumière des découvertes dont fait état le présent article, cette hypothèse nous paraît désormais très peu probable. Elzéar-Alexandre Taschereau, Histoire du Séminaire de Québec [s. d.], MG 17, A3, vol. 345, fol. 5561, Bibliothèque et Archives Canada (BAC); «Lettre de l'abbé Tremblay à l'abbé Glandelet, Paris, 3 mai 1698 », Lettres O, no. 23, ASQ. Voir également: Gallat-Morin et Pinson 2003, 501.

70 «Lettre de M. Thiberge à M. de Bernières, sup. du Séminaire de Québec, Paris, 13 juin 1696 », Lettres O, no. 17 , ASQ. 
vieux continent puisque cela n'aurait pas incommodé le principal intéressé71. Et pour cause: François Hurault et Marie Languille, son beau-père et sa mère, sont désormais établis à La Rochelle. Ses demi-sœurs Marie-Madeleine $\mathrm{Hu}$ rault mariée au marchand Jean Molinier et Élizabeth Hurault mariée au marchand Pierre Laurant y sont également établis. François Grouard passe donc en France en 1699 avec son frère Jean-Baptiste Grouard, veuf de Marguerite Têtu, lequel en cette année 1699 convole avec Françoise Pochon à La Rochelle et s'y établit à son tour ${ }^{72}$. Parents, sœurs utérines et beaux-frères sont à La Rochelle. François Grouard n'est donc pas sans soutien ${ }^{73}$ ni ressources familiales ${ }^{74}$.

Au Séminaire des Missions Étrangères de Paris, on s'inquiète pourtant, on trame pour empêcher le retour de François Grouard au Canada et étouffer ce péché que personne ne semble vouloir nommer et qui, de toute façon, écrit le procureur du séminaire de Québec à Paris, ne serait pas cru par les parents de Grouard, quand bien même on leur en ferait le récit75. À Québec, on appréhende que la famille n'aille plus loin en justice pour exiger une pension ou, à tout le moins, un dédommagement de la part du Séminaire en faveur de leur parent. Advenant une victoire, le séminaire n'aurait pratiquement d'autre choix que d'agréger Grouard à son corps ou, à tout le moins, de l'entretenir jusqu'à sa mort. "Vous n'avez, s'il retourne en Canada, qu'a ne le pas recevoir au Sém[inaire ${ }^{76}$ ", d'écrire Tremblay à Glandelet.

Depuis Paris, tout semble simple. Les directeurs du séminaire sous-estiment pourtant l'entêtement de cette famille marchande qui cherche peut-être moins à sauver l'honneur d'un des leurs qu'à se décharger du poids qu'il représente. Une réclamation contre les directeurs de l'institution est déposée devant la prévôté de Québec. La famille du plaignant demande que François Grouard, ecclésiastique, soit agrégé au Séminaire de Québec et gardé pour le reste de ses jours commel'un de ses membres. Autrement, le Séminaire devrait moralement être tenu à lui verser une rente annuelle de 400 livres sur le fonds que la cour accorde au Séminaire pour le logement, l'entretien et la nourriture des "prêtres usez». Du côté des directeurs, on rétorque que Grouard jouit de son titre clérical et de ses revenus de capellanie, puisqu'étant toujours officiellement chapelain au chapitre de Québec. Le roi ayant fait don de 3000 livres au chapitre pour s'acquitter du chant de l'office divin, chacun des chapelains touche alors

71 «Lettre de M. Tremblay à M. Glandelet, Paris, 8 août 1696 », Lettres O, no. 12, p. 18, ASQ.

72 Contrat de mariage entre Jean Grouard, natif de Québec et Françoise Pochon, 26 janvier 1699. Greffe, de René Rivière, Pierre Soullard et François Soullard, notaire à La Rochelle, 3 E 1812/folios 8-8v, Archives départementales de Charente-Maritime.

73 Contrat de mariage entre Jean Molinier, marchand demeurant à La Rochelle, négociant dans le pays de Canada et Marie Magdeleine Hurault, demeurant à La Rochelle, native de Québec, 3 janvier 1698. Greffe, de René Rivière, Pierre Soullard et François Soullard, notaire à La Rochelle, 3 E 1812/ folios 95-95v, Archives départementales de Charente-Maritime.

74 Reconnaissance faite par Jean Molinier, marchand, et Marie Magdeline Hurault, sa femme, d'avoir entre leurs mains 16 ooo livres appartenant à Marie Languille, veuve du sieur François Hurault; somme à faire valoir sur les effets de la succession dudit feu Hurault tant en France qu'au Canada, 14 janvier 1700. Greffe, de René Rivière, Pierre Soullard et François Soullard, notaire à La Rochelle, 3 E 1812/folio 100, Archives départementales de Charente-Maritime.

75 «Lettre de M. Tremblay à M. Glandelet, 3 mai 1698», Lettres O, no. 23, p. 31, ASQ.

76 «Lettre de M. Tremblay à M. Glandelet, 3 mai 1698 ». Lettres O, no. 23, p. 31, ASQ. 
trois cents livres annuellement tandis que 150 livres sont remis à chaque enfant de chœur. Dans les faits, le titre de chapelain dont jouit Grouard au chapitre ne lui rapporte strictement rien en ces années ${ }^{77}$. Quant à son titre clérical d'une valeur de 75 livres de rente et pension viagère annuelle, Grouard ne peut en avoir la pleine jouissance que dans la mesure où il est ordonné prêtre, selon les termes contenus dans l'acte notarié jadis passé par ses tuteurs ${ }^{78}$. Or il ne l'est pas, n'étant toujours que sous-diacre ${ }^{79}$. Cela dit, l'état ecclésiastique dont il est revêtu depuis son ordination au sous-diaconat incite, en théorie du moins, l'évêque ou le chapitre, en vertu des canons du concile de Trente, à lui assurer un minimum de revenus pour le soustraire à une vie indigente ${ }^{80}$.

À l'âge de 41 ans en 1703, plus personne ne croit en une ordination éventuelle. L'étude des actes notariés qui concernent le réseau familial auquel appartient l'ecclésiastique François Grouard révèle par ailleurs qu'une somme lui sera léguée au décès de sa mère ${ }^{81}$. Sa mère étant toujours vivante, il ne peut toucher l'héritage promis et ne dispose pratiquement de rien pour vivre, comme le révèlent les documents d'archives consultés. Avant 1703, Grouard a dû emprunter pour subsister ${ }^{82}$. En avril de cette même année, le Séminaire des MissionsÉtrangères de Paris, institution jumelle du séminaire des Missions-Étrangères de Québec, lui refuse à son tour la pension qu'il sollicite en raison de ses supposées infirmités ${ }^{83}$. La demande est rejetée du revers de la main sous prétexte qu'il n'est pas agrégé au corps du séminaire. En 1700, le testament de sa mère, Marie Languille, veuve depuis peu de François Hurault, rédigé à La Rochelle en 1700 , qualifie Grouard " [d'] ecclésiastique demeurant en Canada ${ }^{84}$ », et non de prêtre agrégé au séminaire. Tout porte à croire qu’il existe alors une sorte

77 «À l'égard de la capellanie, il n'en peut demander les revenus puisqu'il n'y en a pas». «Lettre de M. Tremblay à M. Glandelet, 3 mai 1698 ", Lettres O, no. 23, p. 31, ASQ.

78 Titre clérical de François Hurault et Marie Languille, son épouse, de la ville de Québec, épouse antérieure de Richard Grouard, pour François Grouard, son fils, 19 novembre 1683. Greffe de Genaple de Bellefonds, F. (1682-1709), ZA41, BAnQ.

79 Dans un document notarié de 1703, on parle de lui comme étant: «Sieur François Grouard prestre», ce qui est évidemment une erreur de la part du notaire, puisque Grouard n'était toujours que sous-diacre. Partage de la succession de feu François Hurault, époux de Marie Languille, veuve en premières noces de Richard Grouard, 26 janvier 1703. Greffe, de René Rivière, Pierre Soullard et François Soullard, notaire à La Rochelle, 3 E 1812/folios 233V-236v, Archives départementales de Charente-Maritime.

80 Session XXI, juillet 1562, décret de réformation, canon 2 : «Il n'est pas séant que ceux qui sont entrés au service de Dieu soient, à la honte de leur profession, obligés à la mendicité ou contraints de gagner leur vie par un moyen sordide». (Leclercq 1938, 420-21).

81 Testament par Marie Languille, veuve du sieur François Hureau, marchand et auparavant veuve de Richard Grouard. Greffe, de René Rivière, Pierre Soullard et François Soullard, notaire à La Rochelle, 26 septembre 1700, 3 E 1812/folios 186v-187v, Archives départementales de Charente-Maritime.

82 «Deux cents quatre-vingt dix-huit livres trois sols deues par le Sieur François Grouard prestre en deux parties[.] L'une au grand Livre et l'autre, le billet du Sr Buisson ». Partage de la succession de feu François Hurault, époux de Marie Languille, veuve en premières noces de Richard Grouard, 26 janvier 1703. Greffe, de René Rivière, Pierre Soullard et François Soullard, notaire à La Rochelle, 3 E 1812/folios 233v-236v, Archives départementales de Charente-Maritime.

83 Archives du Séminaire des Missions-Étrangères de Paris (AMEP), 345a.

84 Testament par Marie Languille, 3 E 1812/folios 186v-187v, Archives départementales de Charente-Maritime. 
de confusion chez les membres du clergé et, surtout chez le clergé missionnaire, quant à la nature de leur lien avec cette institution. Épuisés par le travail dans les missions d'Acadie, l'abbé Le Loutre et d'autres sollicitent d'y être reçus pour y finir leurs jours. La porte du séminaire se ferme impitoyablement devant eux $^{85}$.

\section{SilenCE SUR GrouARD}

Labbé Henri-Jean Tremblay, désormais procureur du séminaire de Québec à Paris ne peut qu'avoir influencé négativement l'opinion à l'endroit de Grouard. À preuve, deux mois après que le conseil des directeurs de la filiale de Paris ait rejeté la demande de pension présentée par Grouard, Tremblay s'enquiert auprès du vicaire général de l'évêque de La Rochelle, lui aussi logé au Séminaire des Missions-Étrangères de Paris, sur la rue du Bac, des moyens pour empêcher le retour de Grouard au Canada, notamment grâce à l'éventuelle intervention de Mgr Champflour. En 1703, le grand vicaire répond à Tremblay que l'évêque de La Rochelle «ne parlera pas que nous ne lui donnions un mémoire sur M. Grouard pour le prier de le retenir à la Rochelle ${ }^{86} »$. Notre ecclésiastique, facteur d'orgue amateur, est donc dans cette ville où sa mère et une partie de sa famille se trouvent. À ce jour, les recherches pour localiser ce mémoire sur Grouard sont demeurées vaines. Toutefois, tout suggère que les directeurs du Séminaire de Québec avaient fourni pareil document à Beauharnois lorsque l'affaire de Grouard fut portée devant lui en 1703. La copie de la sentence rendue le 24 avril précédent par l'intendant rappelle en effet que les supérieurs "citent même quelques-unes de ses actions ${ }^{87}$ ». À l'issue de l'enquête menée par l'intendant Beauharnois, Nicolas Rousselot de La Prairie, beau-frère de Grouard et Jacques Grouard, son frère, sont finalement déboutés le 24 avril $1703^{88}$. Le séminaire ne peut alors que se féliciter de jouir de la protection de l'intendant, une fois de plus ${ }^{89}$.

Grouard regagne probablement Québec vers 1703 ou peu après. Dès lors sa figure s'estompe de plus en plus. En 1714, le chapitre reçoit une gratification de 3 ooo livres pour ses dignitaires et «autres ecclésiastiques qui le composent». L'examen des comptes du chapitre de la cathédrale de Québec ne mentionne plus son nom. Par ailleurs, n'étant pas prêtre, il n'est pas couvert par la gratification de 2000 livres destinée à «l'entretien des prêtres qui ne sont plus en

85 «Mémoire pour les Sieurs Girard, Manach et Le Loutre, Missionnaires du Séminaire des Missions étrangères dans les Indes Occidentales, Appellans comme d'abus. Contre les Superieurs \& Directeurs du Seminaire des Missions Etrangeres, etabli à Paris rue du Bacq, Intimés», Paris, 1764.

86 "Lettre de l'abbé Tremblay à Glandelet, 15 juin 1703», Lettres O, no. 40, p. 12, ASQ.

87 Copie de la sentence rendue par Monsieur de Beauharnois Intendant portant condamnation des demandes et pretentions du $S^{r}$ Rousselot, etc., en faveur du $S^{r}$ François Groüard, Ecclesiastique, son beau frere, contre les Messieurs du Séminaire de Québec, du 24 avril 1703, Séminaire 34, no. 134, ASQ.

88 Requête de Rousselot et Grouard à François de Beauharnois, séminaire 5, no. 76, ASQ; 34, no. 134, ASQ.

89 "Nous sommes ravis de ne nous être pas trompés en vous faisant espérer beaucoup de protection de la part de M. de Beauharnois». Lettre des abbés Louis Tiberge et Jacques de Brisacier aux messieurs du Séminaire de Québec, 23 juin 1703, Lettres M, no. 29, ASQ. 
état de servir ${ }^{\circ} »$. En 1734, la pension et la nourriture au séminaire de Québec inclut, pour le personnel ecclésiastique indispensable: un supérieur, un procureur, un économe, deux maîtres d'école pour le petit séminaire et un professeur pour le grand séminaire ${ }^{91}$. De Grouard, il n'est absolument plus question. Même à la paroisse, où l'orgue a besoin de réparation, c'est à Jacques Pagé dit Quercy, horloger et orfèvre, que l'on confie le travail pour la somme de 132 livres 5 sols $^{92}$.

Issu du milieu des artisans et des marchands de Québec, recruté par Mgr de Laval pour son petit séminaire dès sa puberté, évoluant dans un milieu proche de l'Église, la carrière sans relief de Grouard, son comportement équivoque aux dires des directeurs du séminaire, ses démêlés avec cette institution tout autant qu'un possible absentéisme peuvent expliquer en partie le silence dont son nom fut volontairement entouré par Bertrand de Latour. On ne peut toutefois s'empêcher de relever le fait que Bertrand de Latour ait mentionné cet «ecclésiastique » qui, tout de même, lui était parfaitement connu puisqu'il avait lui-même veillé à lui refaire payer ses honoraires de chapelain dus par le chapitre lui devait. Tout semble donc s'être passé comme si les réalisations de " [l']ecclésiastique, qui a[vait] du génie pour la méchanique» (Latour 1761, 172) et qui avait fait des orgues en bois à Québec étaient dignes de mention dans une chronique historique sur l'Église de la Nouvelle-France mais, qu'inversement, son nom se devait d'être tu dans un ouvrage écrit à la gloire de Mgr de Laval.

Les annales de l'Hôpital général de Québec mentionnent que Grouard vit dans les appartements destinés aux messieurs du clergé depuis 1726. À partir de 1731, comme l'a montré Pinson, le registre du chapitre de Québec indique pour sa part que l'on rétribue désormais des chantres «en la place des chappellains » (Gallat-Morin et Pinson 2003, 67). Sans surprise, le nom de Grouard est inscrit au registre des pensions octroyées par le chapitre dès l'année suivante. Grouard est alors âgé de 70 ans. En 1732, il fait son entrée à l'Hôpital général, cette fois comme pensionnaire. À cette date, Bertrand de Latour, alors doyen du chapitre de la cathédrale de Québec, est toujours supérieur majeur de la communauté de l'hôpital général, et par le fait même connait Grouard ${ }^{93}$. Le registre des pensions de l'institution précise «[qu']est entré Mr François Groüard, âgé de 70 ans, soudiacre et chapelain du chapitre de la cathédrale 94 ». En 1733, il loge toujours avec l'aumônier de l'hôpital dans les appartements

\footnotetext{
90 «Estat des depenses de Canada qui sont payées par le fermier du Domaine d'Occident [1714]». MG1, série $C^{11}$ A, vol. 113, fol. 274-275, BAC.

91 «État des dettes du Séminaire de Québec tant anciennes que nouvelles, des sommes payées au compte et de ce qui reste dû en 1734 suivant les registres et autres pièces justificatives représentées ». MG1-C ${ }^{11}$ A, vol. 107, fol. 378-385v, BAC.

92 Livres de comptes de N.-D.-de-Québec. Archives de l'archidiocèse de Québec, CM2/C1, 1, vol. 1, p. 352v; Louis Beaudet, Recensement de la ville de Québec pour 1716, Québec: A. Côté, 1887, p. 35; Robert Derome, Les orfèvres de Nouvelle-France, Inventaire descriptif des sources, Ottawa, Galerie nationale du Canada (Documents d'histoire de l'art canadien, no. 1), 1974.

93 Annales, 13.14.2.1, p. 293, AHGQ.

94 Registre des pensions particulières, 24.2.7, AHGQ.
} 
destinés au clergé 95 . En cette même année, une inhumation a lieu «en présence du Sr Grouard soudiacre ${ }^{96}$ ». Puis, le 29 novembre 1743, c'est au tour de Grouard de s'éteindre à l'âge de 81 ans ${ }^{97}$. Le nom de celui que nous pensons avoir été le premier facteur d'orgue du Canada s'abîme dès lors dans l'oubli 98 .

\section{Conclusion}

Ainsi, pendant l'intervalle 1685-1715, grâce aux artisans qu'il a su rassembler autour de lui, le séminaire devient un foyer de vie artistique et musicale qui rayonne sur la paroisse de Québec et sa banlieue. Au cours de cette période faste où ecclésiastiques, artistes et artisans unissent leurs forces et leurs talents pour faire du Canada une nouvelle France, autant sur les plans religieux qu'esthétique. Peu à peu, le rêve s'estompe. La belle chapelle du séminaire à laquelle Mgr de Laval tenait tant est réduite en cendres en 1701. Trois plus tard, le sculpteur Denis Mallet meurt, suivi de l'abbé Louis Soumande en 1706, puis c'est le tour de Mgr de Laval en 1708, de la Mère de Saint-Augustin la même année et de l'abbé Leblond en 1715, l'année même où l'éphémère et jeune organiste de la cathédrale de Québec, Jean-Baptiste de Michelance, décède lui aussi99. Privé de ses professeurs, l'école de Saint-Joachim ne reçoit plus d'élèves à partir 1715 et ferme ses portes à jamais. Le théâtre de la vie musicale d'un moment disparait. Les uns après les autres, les acteurs de cette époque tirent leur révérence, Grouard et ses instruments étant les derniers en lice. Une page se tourne indéniablement. Parmi les héritières de cette époque, figurent les religieuses hospitalières de l'hôpital auxquelles l'abbé Serré de La Colombière avait appris «à toucher l'orgue afin de soulager le chant ${ }^{100} »$. Ce que devint ce petit instrument, nous ne saurions le dire.

Avec le recul du temps, on observe que tous les individus ci-haut nommés évoluent dans l'orbite de Québec sur une période relativement courte, qu'ils sont liés entre eux soit par le sang, par l'amitié ou par une filiation institutionnelle et, que de cette synergie des enthousiasmes communiqués par les uns et les autres, nait une vie artistique et musicale. On comprend dès lors que cette activité se dilate et se contracte selon les constellations humaines qui, momentanément, se mettent en place et se déploient dans le paysage colonial. L'effet de leur action sur la société peut être parfois durable, souvent passager. Si

95 En 1738, «la maison est composée de 114 personnes comme suite: 2 ecclésiastiques, 40 religieuses, 47 pauvres, 15 pensionnaires et 10 domestiques ", Annales, 13.14.2.1, p. 390, AHGQ.

96 Registre de catholicité de la paroisse N.-D.-des-Anges de l'Hôpital général de Québec, 9 juin 1738, 8 octobre 1738, AHGQ.

97 Les annales de l'institution notent: «Le 29 novembre décéda dans les appartemens destinés pour les MM du Clergé où il demeurait depuis 11 ans, Mr François Grouard sous diacre et chapelain du chapitre de Québec à l'âge de 81 ans et fut inhumé dans notre eglise par Mr Vallier, théologal de la même cathédrale, assisté du Père M. Imbault chapelain» (Annales, 13.14.2.2, p. 5, AHGQ).

98 Registre du chapitre de Québec, 1684-1778, AAQ, 10-B, p. 44r; Archives nationales d'outremer (ANOM, France), COL C11A 106/fol.270-271v; Quittance par les membres du chapitre de Québec aux religieuses de l'Hôpital-Général, 9 octobre 1742. C11A, 107/fol. 441-441v; AHGQ, Annales, 13.14.2.2/1.9.2, p. 5; Registre des pensions; Registre des baptêmes, mariages et sépultures de la paroisse N.-D.-des-Anges, 25.3.1,1,19,5; Gallat-Morin et Pinson 2003, 67.

99 Nous travaillons actuellement à documenter la biographie de cet organiste.

100 Annales, vol. 2, p. 13, AHGQ. 
aujourd'hui tous les instruments de celui que nous croyons avoir été le premier facteur d'orgue sont disparus, réjouissons-nous cependant que le nom du présumé premier facteur d'orgue de la colonie française d'Amérique sorte enfin de l'oubli et qu'avec lui se révèle une humanité à l'œuvre.

Certes, l'histoire de maistre François Grouard et ses liens avec le monde de la facture instrumentale restent à approfondir. Le présent article, mené sous forme d'enquête policière, a soulevé une hypothèse de recherche qui demande à être vérifiée. Un jour peut-être, des chercheurs trouveront d'autres pièces d'archives inédites qui permettront de valider certaines de nos intuitions et ainsi approfondir nos connaissances sur cet aspect de la vie culturelle de la Nouvelle-France ${ }^{101}$.

\section{RÉFÉRENCES}

Bacqueville (de La Potherie), Claude-Charles Le Roy de. 1753. Histoire de l'Amérique septentrionale, tome 1. Paris: Nyon.

Baillargeon, Noël. 1972. «Le Séminaire de Québec sous l'épiscopat de Mgr de Laval». Les Cahiers de l'Institut d'Histoire (18). Québec: Les Presses de l'Université Laval.

Charlevoix, François-Xavier de. 1744. Histoire et description générale de la Nouvelle France, vol. 5. Paris: Giffart.

Démia, Charles. 1683. Trésor clérical ou conduites pour acquérir et conserver la sainteté ecclésiastique. Lyon: Certes.

Dompnier, Bernard. (à paraître) «Le métier du maître de musique d'église (XVI ${ }^{\text {ème }}$ début XIX ${ }^{\text {ème }}$ siècle). Activités, sociologie, carrières", communication présentée au colloque tenu à Versailles, 8-10 novembre 2017, sous la direction de Bernard Dompnier et Jean Duron.

Furetière, Antoine. 1727. Dictionnaire universel. La Haye: Husson.

Gallat-Morin, Élisabeth, et Jean-Pierre Pinson. 2003. La vie musicale en Nouvelle-France. Québec: Septentrion.

Gallat-Morin, Élisabeth. 2012. L'orgue de 1753 renaît de ses cendres. Québec: Musée de la civilisation.

Gosselin, Amédée. 1911. L'instruction au Canada sous le Régime français (16351760). Québec: Laflamme et Proulx.

Gravé de La Rive, Henri-François. 1786. Transcripta, Séminaire 13, ms. 6, ASQ. Lafontaine, André. 1981. Recensement annoté de la Nouvelle-France. Sherbrooke: A. Lafontaine.

${ }^{101}$ Cette enquête "policière» a nécessité l'appui et les conseils de nombreux chercheurs et professionnels. Je remercie très chaleureusement les personnes suivantes qui ont lu et commenté cet article, apportant leur expertise dans l'un ou l'autres des domaines auxquels se rattache l'histoire de François Grouard, facteur d'orgue amateur. Je nomme les Bernard Dompnier, historien, Élisabeth Gallat-Morin, musicologue, Jean-François Plante et Benoit Vaillancourt, ethnologues, Daniel Drouin et Robert Derome, historiens de l'art ancien du Québec, Stéphane Doyon, de l'atelier Bois du Centre de conservation du Québec, Emmanuel Bernier, historien et organiste, Jean Côté, Claude Lemieux, Benjamin Waterhouse, organistes, Simon Couture et Robin Côté, des ateliers de facture d'orgues Casavant et frères et Juget-Sinclair ainsi que Matthieu Lachance, architecte. Il faut enfin remercier les archivistes qui m’ont patiemment accompagné au cours de cette recherche, à savoir Peter Gagné, Audrey Julien, Pierre Lafontaine et Rénald Lessard. 
Langevin, Edmond-Charles-Hippolyte. 1874. Notice biographique sur François de Laval. Montréal: Lovell.

Latour, Bertrand de. 1761. Mémoires sur la vie de M. de Laval, premier évêque de Québec. Cologne: Motiens.

Leclercq, Henri.1938. Histoire des conciles: D'après les documents originaux, par Charles-Joseph Hefele, traduite en français avec des notes critiques et bibliographiques par Dom H. Leclercq, et continuée jusqu'à nos jours, tome 10. Paris: Letouzey et Ané.

Mersenne, Marin. 1636. Harmonie universelle, contenant la théorie et la pratique de la musique. Paris: Cramoisy.

Payer, Claude, et Daniel Drouin. 2016. Les tabernacles du Québec des XVIIème et XVIII'me siècles. Québec: Les Publications du Québec.

Plante, Jean-François. 2010. «François Dumontsard et la Nouvelle-France: parcours d'un musicien auvergnat sur deux continents au XVII ${ }^{\mathrm{ème}}$ siècle». Les Bas Chœurs d'Auvergne et du Velay: Le métier de musicien d'Église aux XVII ème et XVIII'me siècles, sous la dir. de Bernard Dompnier, 191-204. Clermont-Ferrand: Presses Universitaires Blaise-Pascal.

Porter, John R., et Jean Bélisle. 1986. La sculpture ancienne au Québec, Trois siècles d'art religieux et profane. Montréal: Les Éditions de l'Homme.

Porter, John R. 1982. "L'ancien baldaquin de la chapelle du premier palais épiscopal de Québec, à Neuville». Annales d'histoire de l'art canadien 7(2). $180-201$

Taschereau, Elzéar-Alexandre. s.d. Histoire du Séminaire de Québec, manuscrit n. d., Bibliothèque et Archives Canada, MG 17, A3, vol. 345, folio 5561.

Têtu, Henri. 1896. Histoire du palais épiscopal de Québec. Québec: Pruneau et Kirouac.

Trudel, Jean. 1969 [2003]. «Leblond de Latour, Jacques». Dictionnaire biographique du Canada (DBC), vol. 2. Université Laval/University of Toronto. Consulté le 6 mai 2020, à l'adresse http://www.biographi.ca/fr/bio/leblond de latour_jacques_2F.html.

Vachon, André. 2003 [1966]. "Jolliet, Louis». Dictionnaire biographique du Canada, vol. 1. Université Laval/University of Toronto, 2003. Consulté le 6 mai 2020, à l'adresse http://www.biographi.ca/fr/bio/jolliet_louis_1F.html.

—_. 1968. «Inventaire des biens de René-Louis Chartier, sieur de Lotbinière (Québec, 13-17 juin 1701)». Revue d'histoire de l'Amérique française 21(4): 803-824.

\section{Figures}

1. Orgue de bois placé à la tribune de la chapelle du palais épiscopal, ca 1700. Modélisation de l'orgue par Matthieu Lachance, architecte, d'après les recommandations de Robin Côté, facteur d'orgues de la maison Juget-Sinclair et les plans du palais épiscopal dressés par Gaspard-Joseph Chaussegros de Léry. Sources: Plan du Premier Etage du Palais Episcopal (1743), Bibliothèque et Archives Canada (BAC), item 40146; Henri Beau, Sulpicien XVII'me siècle, aquarelle. BAC, no. d'acquisition 1933-188-1, C-0oo182. 
2. Coupe longitudinale de la chapelle du palais épiscopal avec l'orgue à la tribune, ca 1700.

Modélisation de la chapelle, de l'orgue et reconstitution partielle du mobilier liturgique par Matthieu Lachance, architecte, d'après les plans du palais épiscopal dressés par Gaspard-Joseph Chaussegros de Léry et les recherches menées par Claude Payeur et Daniel Drouin sur les tabernacles. Sources: Plan du Premier Etage du Palais Episcopal (1743), Bibliothèque et Archives Canada (BAC), item 40146; Henri Beau, Sulpicien XVIIème siècle, aquarelle. BAC, no. d'acquisition 1933-188-1, C-0o0182; Claude Payer et Daniel Drouin, Les tabernacles du Québec des XVII ème et XVIII ème siècles, Québec, Les Publications du Québec, 2016, p. 65 et 237.

\section{RÉSUMÉ}

Écrit sous forme d'enquête policière, cet article se penche sur une affirmation émise par le premier biographe de Mgr de Laval (1623-1708) voulant qu'un ecclésiastique, dont il tait le nom, ait fabriqué des orgues de bois pour les églises de la ville de Québec et de ses environs. L'auteur de cet article formule ici une hypothèse de recherche sur l'identité et la vie de ce premier facteur d'orgue canadien en s'appuyant sur un faisceau d'indices trouvés dans les archives relatives à l'époque de la Nouvelle-France. In fine, cet article se veut une réflexion sur le contexte culturel qui prévaut à Québec au tournant du XVIII siècle et une invitation faite aux chercheurs à poursuivre cette investigation qui relance le débat sur la genèse de la facture d'orgue au Canada.

Mots-clés: facture d'orgue, colonie, Québec

\section{ABSTRACT}

Written in the form of a police investigation, this article examines a claim made by the first biographer of Mgr. de Laval (1623-1708) that a clergyman, whose name he did not mention, made wooden organs for churches in Quebec City and its surroundings. The author of this article formulates here a research hypothesis on the identity and life of this first Canadian organ maker based on several clues discovered in archives relating to the New France era. Ultimately, this article is a reflection on the cultural context that prevailed in Quebec City at the turn of the 18th century and an invitation to researchers to pursue this investigation, which reopens the debate on the genesis of organ making in Canada.

Keywords: organ making, colony, Quebec

\section{BIOGRAPHIE}

Paul-André Dubois est professeur titulaire au Département des Sciences historiques de l'Université Laval. Son champ d'expertise couvre la vie culturelle dans les colonies nord-américaines et l'histoire des missions françaises chez les Amérindiens. 